\title{
A Comprehensive Bioinformatic Analysis of RFC1/2/3/4/5 As Significant Clinical Indicators in The Diagnosis and Prognosis of Low-Grade Glioma
}

\section{Yuefeng Wang}

Sun Yat-sen University First Affiliated Hospital

\section{Liyun Huo}

Sun Yat-Sen University 2nd Affiliated Hospital: Sun Yat-Sen Memorial Hospital https://orcid.org/00000003-2074-4907

Zunfu Ke ( $\square$ kezunfu@mail.sysu.edu.cn )

Sun Yat-sen University First Affiliated Hospital https://orcid.org/0000-0002-6251-7246

\section{Primary research}

Keywords: Replication factor C, low-grade glioma, bioinformatic analysis, RFC1, RFC2, RFC3, RFC4, RFC5

Posted Date: January 7th, 2021

DOI: https://doi.org/10.21203/rs.3.rs-139589/v1

License: (c) (i) This work is licensed under a Creative Commons Attribution 4.0 International License. Read Full License 


\section{Abstract}

Background: Replication factor C (RFC) proteins play a very important role in nuclear DNA replication, mismatch repair and cell cycle checkpoint pathways. However, the relationship between RFCs and brain tumors is still unclear, especially the diagnostic and prognostic significance of RFCs in low-grade glioma.

Methods: In our study, we applied the Oncomine, GEPIA, Human Protein Atlas, cBioPortal, STRING, LinkedOmics and Tumor Immune Estimation Resource (TIMER) databases to analyze the transcriptional and survival data of RFCs in brain and central nervous system (CNS) cancer, especially in low-grade glioma.

Results: We found that RFCs were highly expressed in brain and CNS cancer, including low-grade glioma. The transcriptional levels of RFCs were also associated with the tumor stages. Moreover, the survival analysis of RFCs in low-grade glioma patients revealed that enhanced expression of RFCs led to poorer prognosis. RFCs and their 50 frequently altered neighbor genes were found enriched in certain pathways. We also discovered the kinase targets, transcription factor targets and miRNA targets of RFCs in lowgrade glioma. RFCs also showed positive correlation with certain infiltrated immune cells in low-grade glioma.

Conclusions: These implied that RFCs are the possible biomarkers of the diagnosis and prognosis of lowgrade glioma.

\section{Background}

Glioma accounts for a great proportion in the primary malignant brain tumors(1). Basing on the World Health Organization (WHO) classification, gliomas in WHO grade冈or冈are identified as low-grade gliomas (LGG)(2). It arises from supporting glial cells of the central nervous system (CNS)(3). Patients with WHO grade $\triangle$ LGG can be cured successfully by surgery, on the contrary, patients with WHO grade $\otimes$ LGG are hard to be curable due to the diffusion and infiltration of the tumor(4). Because of its diffusive character, WHO grade $₫$ glioma is often called diffuse low-grade glioma (DLGG), including astrocytoma, oligodendroglioma and mixed oligoastrocytoma(1). Moreover, DLGG can grow at an average rate of 4$5 \mathrm{~mm}$ per year, resulting in a slow malignant transformation which will lead to death of patients(5). The current therapeutical methods for DLGG mainly include surgical resection, radiation and chemotherapy(6). However, the recurrence rate is still high in LGG patients with a current mean survival for less than 10 years $(4,7,8,9)$. Therefore, new molecular targets with remarkable clinical significance in LGG diagnosis and prognosis are in an urgent need.

Extracted from the human cervical cancer cells HeLa, Replication factor C (RFC) family complex contains RFC1, RFC2, RFC3, RFC4 and RFC5 subunits $(10,11)$. RFCs play a pivotal role in telomere maintenance, nuclear DNA replication, mismatch repair, and nucleotide excision repair, so the changed expression of RFCs can not only influence the physiological processes in normal cells, but also stimulate the progression of many cancer types $(11,12)$. Based on the previous studies, each RFC subunit has its 
unique functions in normal cell processes. RFC1 contains the main DNA binding area and directly participates in DNA replication and repair(13). RFC2 is correlated with cell cycle checkpoint signaling pathway and it also plays a part in PCNA-related mismatches repair after the DNA damage(14). RFC4 functions in DNA damage checkpoint pathways while RFC5 is needed for opening PCNA clamp during DNA replication $(15,16)$. Moreover, the interaction between RFC1 and RFC complex which consists of RFC1, RFC2 and RFC5 needs the participation of RFC3(17).

RFCs also play a very important role in cancer proliferation, migration and invasion(11). Many previous researches have reported the subunits of RFCs to be remarkable differentially expressed genes when comparing tumor tissue and normal tissues in many cancer types, such as breast cancer, nasopharyngeal carcinoma, ovarian tumor, acute myeloid leukemia and so on(18, 19, 20, 21, 22, 23, 24, 25). Some of the RFCs subunits including RFC2, RFC4 and RFC5, have been reported in glioma and glioblastoma, however, the studies are not sufficient $(26,27,28,29,30)$. The studies of RFC1 and RFC3 in brain and central nervous system cancer can rarely be found. With the development of sequencing technology and bioinformatic analysis, we wondered if RFCs could be clinical biomarkers in the diagnosis and prognosis of LGG patients. In our study, we completed a comprehensive bioinformatic analysis of the expression of RFCs gene family in LGG patients and explored the diagnostic and prognostic significance of RFCs in patients with LGG. The research and analysis were based on several open-source databases and the results of our study can provide information for the development of molecular diagnosis and targeted therapy in LGG.

\section{Materials And Methods}

\section{ONCOMINE database}

ONCOMINE database (www.oncomine.org) is a comprehensive cancer microarray database with precise data-mining functions based on website(31). We used ONCOMINE to look in the expression patterns of RFCs in different kind of cancers with the p-value $<0.05$, fold change $>1.5$ and a gene rank in the top $10 \%$ set for the screening. We verified the data significance by the Student's t-test. Moreover, we also used ONCOMINE to dig the expression levels of RFCs in different grades of LGG and Brain cancer patients.

\section{GEPIA database}

GEPIA (http://gepia.cancer-pku.cn/index.html) is an online data-mining tool based on the RNA sequencing data from TCGA and GTEx and it was developed by Tang et al(32). We evaluated the expression profiles of RFCs in patients with LGG by GEPIA and assessed the statistical significance by the log2 Fold change cutoff at $1, \mathrm{p}$-value cutoff at 0.01 . We also use GEPIA to analyzed the survival plots of RFCs in LGG patients with the expression cutoff $75 \%$ as RFCs high expression group and the expression cutoff of $25 \%$ as RFCs low expression group. What's more, we evaluated the expressive correlation between RFCs one to one by GEPIA with the Pearson method and take p-value $<0.05$ as the criteria of significance. GEPIA2 database was used to identify the 50 frequently altered neighbor genes of RFCs. 


\section{Human Protein Atlas database}

The Human Protein Atlas database(https://www.proteinatlas.org) contains profiling expression patterns of immunohistochemistry(IHC) and immunofluorescence(IF) in normal and cancer tissues(33). In current study, Human Protein Atlas provided us for the immunohistochemistry staining images of RFCs in normal brain tissues and brain glioma tissues.

\section{cBioPortal database}

CBioPortal database(www.cbioportal.org) is an online resource storing readily understandable genetic, epigenetic, gene expression, and proteomic events. It also provides a platform for analysis of gene mutation patterns in different cancers(34). We used cBioPortal for RFCs mutation analysis in LGG patients based on the TCGA, with a mRNA expression z-score(RNAseq V2 RSEM) for diploid samples at \pm 2.0. The survival analysis for RFCs mutations was also carried out by cBioPortal and the survival curves of overall survival (OS) and disease free survival(DFS) were considered significant when $p$-value $<0.05$.

\section{STRING database and Cytoscape}

STRING database(https://string-db.org/) provided free public information of protein-protein associations and their connectivity network with computational predictions(12). Cytoscape is a free resource software to construct and exhibit the biomolecular interaction networks with input data of molecules interactions(35). We predicted our RFCs and 50 frequently altered neighbor genes protein-protein interaction (PPI) network with STRING database and got the nodes information of the network. Then, we input the information into Cytoscape and constructed our PPI network frameworks.

\section{$R$ packages for $G 0$ and KEGG enrichment analysis}

To performed the Gene Ontology(GO) enrichment analysis and Kyoto Encyclopedia of Genes and Genomes(KEGG) pathway enrichment analysis of RFCs and 50 frequently altered neighbor genes, we applied the "clusterProfiler" R package and set the p-value as 0.05 for statistical significance(36). Then, the GO enrichment plots were drew by "Goplot" R package(37) and the KEGG enrichment plots were drew by "pathview" R package(38).

\section{LinkedOmics database}

LinkedOmics (http://www.linkedomics.org/) database is an open source for multi-omics data and clinical data of 32 cancer types based on the TCGA and provides comprehensive analysis by the LinkedOmics module, the LinkFinder module and the LinkInterpreter module(39). We predicted the kinase targets, the miRNA targets and the transcriptional targets of RFCs on LinkedOmics by the method of by Gene Set Enrichment Analysis (GSEA) in patients with LGG. A minimum number of gene(size) of 3 and a simulation of 500 was set. The data were considered significant when $<0.05$.

\section{TIMER database}


Tumor Immune Estimation Resource (TIMER; https://cistrome.shinyapps.io/timer/) provides investigation of the correlation between molecular characterization and tumor-immune interactions. Levels of six tumor-infiltrating immune subsets were observed from 32 cancer types(40). TIMER database was applied to evaluate the correlation between RFCs expression and the six kinds of immune cells infiltration in LGG patients. The survival analysis influenced by the immune cell infiltration in patients with LGG was also carried out on TIMER and the p-value was set at 0.05 . Moreover, the Cox proportional hazard model for LGG patients was also constructed and calculated by TIMER.

\section{Results}

Over-expression of RFCs family was found in Brain and Central Nervous System (CNS) cancer patients.

At the beginning of our study, we looked into the different mRNA expressions of RFCs between Brain and CNS cancer tissues and normal tissues via ONCOMINE database. A comprehensive view of RFCs expression in different types of cancers was shown in Fig. 1. Moreover, focusing on Brain and CNS cancer, several datasets in table 1 demonstrated that the mRNA of RFC1/2/3/4/5 was significantly overexpressed in cancer tissues rather than normal tissues. RFC1 not only showed elevated expression in Desmoplastic Medulloblastoma (fold change $=1.894$ ) via Pomeroy Brain dataset $(41)$, but also in Glioblastoma (fold change $=1.594$ ) through TCGA Brain dataset. The mRNA expression of RFC2 raised in Glioblastoma in different datasets, including Bredel Brain 2 (fold change $=1.769)(42)$, Sun Brain (fold change $=1.679)(43)$, TCGA Brain (fold change $=1.706$ ) and Murat Brain (fold change $=1.719)(44)$. RFC3 transcription was found increased in Glioblastoma in Liang Brain (fold change $=1.617)(45)$. In French Brain dataset(46), RFC3 was found increased in Anaplastic oligoastrocytoma (fold change $=3.709$ ) and Anaplastic Oligodendroglioma (fold change $=2.454$ ). Bredel et al. $(42)$ also reported a raise of RFC3 both in Anaplastic Oligodendroglioma (fold change $=2.024$ ) and Oligodendroglioma (fold change $=1.781$ ). Glioblastoma exhibited higher expression of RFC4 in Murat Brain (fold change $=2.572)(44)$, Bredel Brain 2 (fold change $=1.634)(42)$, Sun Brain (fold change $=1.75)(43)$ and Liang Brain (fold change $=1.813$ ) (45). Moreover, RFC4 also showed an enhanced expression in Anaplastic Oligodendroglioma (fold change $=2.293)(46)$, Anaplastic Astrocytoma (fold change $=1.543)(43)$ and Oligoastrocytoma (1.753) (45). Sun et al. discovered an increased expression of RFC5 in Glioblastoma (fold change $=1.800$ ), Anaplastic Astrocytoma (fold change $=1.799$ ) and Oligodendroglioma (fold change $=1.600$ ). French et al. demonstrated that RFC5 mRNA expression was stimulated in Anaplastic Oligodendroglioma (fold change $=1.831$ ) and Anaplastic Oligoastrocytoma (fold change $=2.51$ ). What's more, over-expressed RFC5 was also detected in Glioblastoma respectively through Murat Brain dataset (fold change $=2.431$ ) and TCGA Brain dataset (fold change $=3.683$ ). Pomeroy et al. also reported an increase of RFC5 in Desmoplastic Medulloblastoma (fold change $=1.894$ ).

The mRNA expression of RFCs was elevated in low-grade glioma (LGG) patients.

To further explore the expression of RFCs in low-grade glioma (LGG) and normal tissues, we conducted an analysis via GEPIA and GTEx databases, which were entirely different bases from Oncomine. From the 
expression profile showed in Fig. 2, RFC1 and RFC3 showed significantly higher expression in LGG than normal tissues $(p<0.05)$. Although RFC2, RFC4, RFC5 got higher average expression in LGG tissues, the differences were lack of statistical significance $(p>0.05)$.

Then, the protein expression patterns of RFCs were analyzed on the Human Protein Atlas database. As the immunohistochemical photos displayed in Fig. 3, higher expression of RFC2, RFC4, RFC5 were detected in brain glioma than in normal brain tissues, while RFC1 and RFC3 were both considered high expression in brain glioma tissues and normal brain tissues.

In conclusion, the mRNA expression and protein expression of certain RFCs were enhanced in LGG patients.

Correlation between expression profiles of RFCs and the pathological grades in low-grade glioma.

After demonstrated the enhanced expression of RFCs in LGG, we wondered if there was a correlation between RFCs expression and higher pathological grade in LGG. To seek for the answer, we analyzed the data on Oncomine and GEPIA. As data presented in Fig. 4A, RFC1, RFC2 and RFC3 showed a significantly higher expressed in grade 3 LGG patients than in patients with grade 2 LGG, while the results in RFC4 and RFC5 were lack of statistical significance. Moreover, in Sun Brain dataset(43), higher mRNA transcriptions of RFC2, RFC3, RFC4 and RFC5 were detected in patients with grade3 or grade4 tumors than in grade2 tumors (Fig. 4B). In short, the expression profiles of RFCs showed a significant correlation with the pathological grades of LGG patients.

The prognostic value of RFCs expression in LGG patients.

To find out if higher RFCs expression were significantly correlated to the shorter overall survival (OS) and disease-free survival (DFS), we analyzed the expression profiles and the clinical data of LGG patients in GEPIA. As shown in Fig. 5, the cutoff of high expression group was $75 \%$ while the cutoff of low expression group was set for $25 \%$. Surprisingly, except for the correlation between DFS and the expression of RFC4 was lack of statistical significance ( $p>0.05)$, other expression of RFCs showed negative association with OS and DFS in patients with LGG. In other words, all 5 RFCs were associated with poorer prognosis. It was clear that higher expression of RFCs was correlated with shorter OS and DFS.

Prognostic significance of RFCs genetic mutations and the correlation between the expression of RFCs in LGG patients.

Next, we assessed the mutations of RFCs in LGG patients by the online tool cBioPortal for low-grade glioma based on TCGA. As Fig. 6A and 6B showed, RFCs were altered in $41.79 \%$ of patients with Anaplastic Astrocytoma, $32.26 \%$ of patients with Astrocytoma, $16.22 \%$ of patients with Oligoastrocytoma, $15.56 \%$ of patients with Anaplastic Oligoastrocytoma and in $9.09 \%$ of patients with Oligodendroglioma. Next, we analyzed the RFCs mutation with the patient's prognosis in LGG. As in Fig. 6C, we discovered an evident correlation between the higher mutations of RFCs and the lower overall survival in patients with 
LGG ( $p=0.0241)$ while the correlation between the mutations of RFCs and the disease-free survival was lack of statistical significance. Then we evaluated the correlation between RFCs one to one by GEPIA, the result showed significantly positive association between RFC1 and RFC2, RFC1 and RFC3, RFC1 and RFC4, RFC1 and RFC5, RFC2 and RFC3, RFC2 and RFC4, RFC2 and RFC5, RFC3 and RFC4, RFC3 and RFC5, RFC4 and RFC5 $(P<0.05)$. The correlation rates were shown in Fig. 6D.

Predicted functions and pathways of the mutations in RFCs and their 50 frequently altered neighbor genes in LGG patients.

In order to find out the correlation and functions of RFCs, we first analyzed the protein-protein interaction (PPI) network of different expressed RFCs on STRING (Fig. 7A). Then, we found out the 50 neighbor genes that were associated with RFCs mutations most frequently by GEPIA2 and constructed the PPI network with RFCs and their 50 neighbor genes with STRING and Cytoscape (Fig. 7B). Next, we enriched RFCs and their 50 frequently altered genes in GO and KEGG by R packages "clusterProfiler", "GOplot" and "pathview". As shown in Fig. 7C, biological process, such as G0:0007059 (chromosome segregation), GO:0006260 (DNA replication), G0:0098813 (nuclear chromosome segregation), G0:0000819 (sister chromatid segregation) and G0:0000070 (mitotic sister chromatid segregation) were evidently associated with RFCs and their 50 neighbor genes. In cellular components, G0:0098687 (chromosomal region), GO:0000775 (chromosome, centromeric region), GO:0000776 (kinetochore), GO:0000777 (condensed chromosome kinetochore) and G0:0005819 (spindle) were significantly influenced by the RFCs and their 50 neighbor genes. What's more, molecular functions such as G0:0003678 (DNA helicase activity), G0:0140097 (catalytic activity, acting on DNA), G0:0017116 (single-stranded DNA helicase activity), G0:0008094 (DNA-dependent ATPase activity) and G0:0004386 (helicase activity) were closely related to RFCs and the 50 neighbor genes. Other enriched GO pathways were exhibited in Additional file 1. In KEGG pathways analysis with RFCs and frequently altered genes, 8 pathways were enriched as Fig. 8A showed, including hsa03030 (DNA replication), hsa04110 (Cell cycle), hsa03430 (Mismatch repair), hsa03420 (Nucleotide excision repair), hsa04114 (Oocyte meiosis), hsa04115 (p53 signaling pathway), hsa03440 (Homologous recombination), hsa03460 (Fanconi anemia pathway). The two most enriched pathways were shown in Fig. 8B and 8C. The p-value and enriched genes were precisely recorded in Additional file 2.

Kinase targets, miRNA targets and Transcription factor targets of RFCs in patients with LGG.

In order to explore more molecules and functions correlated to RFCs, we predicted the kinase targets, miRNA targets and Transcription factor targets through LinkedOmics database. The results were shown in table 2. ATM and CDK1 were the top two kinases related to RFC2, ATR and PLK1 showed association with RFC2, PLK1 and CDK1 were two kinase targets influenced by RFC3, PLK1 and ATR were evidently correlated to RFC4, ATM and ATR were top two kinases targeted by RFC5. Speaking of miRNA targets, only RFC1 had more than one closely correlated miRNA targets and MIR-144, MIR-381 were the top two. Moreover, only MIR-144 was significantly associated with RFC5, while other miRNA targets predicted were 
lack of statistical significance. The enrichment of transcription factor targets of RFCs were mainly related to E2F families, including V\$E2F_Q4, V\$E2F_Q6, V\$E2F_Q3, V\$E2F1_Q6, V\$E2F4DP1_01.

The relation of Immune Cell Infiltration and the RFCs gene family in patients with LGG.

To assessed the RFCs related immune cell infiltration, we analyzed the data by TIMER, an online tool based on TCGA. The results were shown in Fig. 9A. RFC1 had a positive correlation with CD8 $+\mathrm{T}$ cells (Cor $=0.434, p=2.01 \mathrm{e}-23), \mathrm{CD} 4+\mathrm{T}$ cells (Cor $=0.22, p=1.30 \mathrm{e}-06), \mathrm{B}$ cells (Cor $=0.396, p=2.05 \mathrm{e}-19)$ and other innate immune cells. RFC2 also had a positive correlation with CD8 $+\mathrm{T}$ cells (Cor $=0.208, p=4.44 \mathrm{e}-$ 06), CD4 + T cells (Cor $=0.288, p=1.61 e-10)$, B cells (Cor $=0.35, p=3.29 e-15)$ and other innate immune cells. Although RFC3 had a positive correlation with CD8 + T cells (Cor $=0.376, p=1.80 \mathrm{e}-17$ ), B cells (Cor $=0.225, p=6.43 e-07$ ) and other innate immune cells, the correlation rate was lower in innate immune cells infiltration. Moreover, the correlation between RFC3 and CD4 + T cells was lack of statistical significance. RFC4 had a positive correlation with CD8 + T cells (Cor $=0.115, p=1.16 e-02), B$ cells (Cor $=$ $0.152, p=8.85 e-04)$, Macrophage cells (Cor $=0.117, p=1.08 \mathrm{e}-02)$ and Dendritic cells (Cor $=0.136, p=$ 3.03e-03) while its correlation with CD4 + T cells and Neutrophil cells was not statistically significant. Like RFC1 and RFC2, the correlations between RFC5 and infiltrated immune cells were positive, including CD8 $+T$ cells (Cor $=0.186, p=4.27 e-05), C D 4+T$ cells $(C o r=0.181, p=7.42 e-05), B$ cells $($ Cor $=0.219, p=$ 1.33e-06) and other innate immune cells. Apart from the correlation research, we also explored the prognostic significance of immune cell infiltration in LGG patients. As shown in Fig. 9B, the infiltration of B cells, CD $8+T$ cells, CD4 + T cells, Macrophage cells, Neutrophil cells and Dendritic cells were all associated with poorer prognosis in patients with LGG. Moreover, we also calculated the correlation between the expression of RFCs and the infiltration of immune cells by the Cox proportional hazard model on the TIMER online tool. As shown in Table 3, the model contains the confounding factors including B cells, CD $4+T$ cells, CD $8+T$ cells, Macrophage cells $(p=0.010)$, Neutrophil cells, Dendritic cells, RFC1, RFC2 $(p<0.001), \operatorname{RFC3}$ RFC4 $(p=0.006)$ and RFC5.

\section{Discussion}

RFCs are significant molecules involved in several physiological cell processes including DNA replication, DNA damage and mismatches repair, cell cycle checkpoint pathway and so on. However, the abnormal expression of RFCs will break the order and triggered oncological changes in human cells. The oncogenic role of RFCs has been reported in many cancer types. In brain and CNS cancers, some RFCs have been reported as remarkable overexpression genes in glioma and glioblastoma. For example, Ho et al. demonstrated that patients with higher grade of glioblastoma tend to express higher RFC2 and result in the resistance to temozolomide, which could be suppressed by miR-4749-5p(27). Peng et al. reported that overexpression of RFC5 could lead to a temozolomide resistance in human glioma cells(47). Certain bioinformatic analysis digging in the differentially expressed gene in glioblastoma tissues and normal tissues have illustrated that the expression of some RFCs was stimulated in cancer tissues rather than normal tissues $(28,29,30)$. However, the specific function research for RFCs in brain and CNS cancers are still insufficient. In our study, we looked into the expression profile of RFCs in low-grade glioma patients 
and explored the clinical significance of RFCs in the diagnosis and prognosis in LGG by in-depth and comprehensive bioinformatic analysis.

Among the RFCs, RFC1 located within the human chromosomal segments 4p13-p14, containing the DNAbinding area and participating in the mismatches repair of DNA damage(48). Although Moggs et al.(18) have reported that genes related to cell proliferation such as RFC1 were downregulated by estrogen E2 and inhibit the growth of MDA-MB-231 breast cancer cells, the studies about the relationship between RFC1 and cancers were inadequate, not to mention the research on RFC1 and LGG. In our study, by analyzing the ONCOMINE datasets and GEPIA database, we discovered that the expression of RFC1 was enhanced in LGG tumor tissues rather than the normal tissues. Moreover, the expression level of RFC1 was related to the tumor grade in ONCOMINE datasets. The survival analysis of RFC1 in patients with LGG showed that higher expression of RFC1 was associated with poorer OS and PFS. What's more, the expression of RFC1 was positively related to certain immune cells infiltration, altering the immune status in LGG patients. ATM and CDK1 were the top two kinases targets influenced by RFC1 in LGG, they had been reported to induce the resistance to radiation therapy and stimulate the progression of gliomas(49, $50,51)$. Certain miRNA targets and transcription factor targets were also predicted in order to provide additional information for further confirmation research on RFC1 and LGG.

RFC2, being the subunits of RFCs, located within the human chromosomal segments $7 q 11.23$, plays a part in DNA replication repair and cell cycle checkpoint pathway $(14,48)$. There were many studies about RFC2 and certain cancers, most of which stated that RFC2 was obviously upregulated in cancer tissues $(19,28,52,53,54)$. Ho et al(27). demonstrated that impaired the activation of RFC2 signaling could enhance the temozolomide cytotoxicity to glioblastoma. In our study, we reconfirmed that the expression of RFC2 was stimulated in brain tumor tissues by Human Protein Atlas database and ONCOMINE datasets. Data of LGG patients from TCGA also revealed that the expression of RFC2 was remarkably related to the grade of LGG. Analyzed by GEPIA, RFC2 expression levels also influenced the clinical outcomes in LGG patients by cut down their OS and DFS. The immune analysis also showed that RFC2 was related the immune cells infiltration, exerting immune effects on LGG patients. ATR and PLK1 were the predicted kinase targets of RFC2 in LGG patients. ATR can activate the checkpoint of G2/M cell cycle thus ATR inhibitors have been developed as antitumor agents $(55,56)$. Shi et al. proved that the combination of Temozolomide and siPLK1 enhanced the anti-tumor effect of Temozolomide in glioma patients. E2Fs, the predicted transcription targets of RFC2 might had a synergistic effect with RFC2 in LGG patients, which need further confirmation.

RFC3 is located within the human chromosomal segments 13q12.3-q13, acting as a media to combine RFC1 and RFCs complex (RFC1, RFC2, RFC5) $(17,48)$. RFC3 had been reported high expression in certain types of cancer tissues $(20,21,22)$. Gong et al.(57) demonstrated that RFC3 could induce epithelialmesenchymal transition in lung adenocarcinoma cells through the Wnt/ $\beta$ catenin pathway. However, the research of RFC3 in glioma area need to be developed. In our study, we found that the expression of RFC3 was higher in LGG tissues by the analysis of GEPIA database. The correlation between RFC3 and the LGG grade was clarified. An enhanced expression of RFC3 was also associated 
with shorter OS and DFS, resulting in a poorer prognosis of LGG patients. RFC3 had positive correlation with several infiltrated immune cells except for CD4 + T cells. PLK1 and CDK1 were predicted as the kinase targets of RFC3 while E2Fs were predicted as transcriptional factor targets for RFC3 in LGG. Chae et al.(58) have demonstrated an indirect relation between E2F and RFC3 to stimulate the progression in the KG-1 acute myeloid leukemia cell line, however, the direct interaction between E2F and RFC3 in LGG development needs further experimental evidence.

RFC4 plays an important role in DNA damage checkpoint pathway and has been reported to enhance the anti-tumor effect of chemotherapies based on DNA-damaging $(15,16)$. The location of RFC4 on human chromosomal segments is 3q27(48). RFC4 was widely reported to be an overexpressed gene in several cancer types and induced tumor progression $(23,24,59)$. In brain cancer area, Tang et al. reported the increased expression of RFC4 in human glioblastoma tissues. However, other reports about RFC4 and brain cancers were blank. In our bioinformatic analysis, samples in ONCOMINE datasets and Human Protein Atlas revealed an enhanced expression of RFC4 in glioma tissues. Moreover, in both TCGA datasets and ONCOMINE datasets, RFC4 expression was obviously associated with the tumor grade in LGG patients. The OS of LGG patients was also shorten when RFC4 was upregulated. The correlation between RFC4 and immune cell infiltration was not as strong as other RFCs. PLK1 and ATR were predicted as the kinase targets of RFC4, which were supposed to induced the progression of LGG. The E2F family were also predicted to correlated RFC4. However, the prediction by bioinformatic analysis must be verified by reliable experiments.

RFC5 is located within the human chromosomal segments $12 q 24.2-q 24.3$ and plays a very important part in opening the PCNA clamp in cell proliferation process $(11,48)$. The oncogenic function had been reported in other cancer types such as oropharyngeal squamous cell carcinomas, hepatocellular carcinoma, lung cancer and so on. $(25,60,61)$. Moreover, Yang et al. reported that the stimulated expression of RFC5 was found in glioblastoma patient tissues. Other studies about RFC5 and LGG were rare. In our analysis of ONCOMINE database and Human Protein Atlas database, RFC5 was highly expressed in glioma and other brain and CNS cancers. In ONCOMINE datasets, RFC5 was also related to brain tumor grades. The survival analysis conducted by GEPIA showed that the enhanced transcription of RFC5 was associated with shorter OS and PFS in LGG patients. It means RFC5 would be a significant biomarker in the diagnosis and prognosis of LGG patients. Like RFC1 and RFC2, RFC5 was strongly associated with the infiltration of different immune cells in LGG, modulating the immune environment of LGG. ATM and ATR were the predicted downstream kinase targets of RFC5, which needed furthermore evidence.

There were still some limitations in our research. Due to the limit of bioinformatic analysis, we need larger sample sizes of LGG patients to reconfirm our conclusion. Moreover, the correlation between RFCs and other molecules should be verified by more experimental evidence. However, we believed that our study about RFCs and LGG could provide hints for researchers in the future. 
In conclusion, our study conducted a comprehensive bioinformatic analysis about RFCs and LGG patients. The expression of RFCs was enhanced in brain and CNS cancers while RFC1 and RFC3 were significantly stimulated in LGG tissues. Moreover, the RFCs were also associated with tumor grade. All the RFCs showed clinical significance in diagnosis and prognosis of LGG, which suggested RFCs being new biomarkers in LGG.

\section{Abbreviations}

RFC: Replication Factor C

CNS: Central Nervous System

LGG: Low-grade Glioma

DLGG: Diffuse Low-grade Glioma

PCNA: Proliferating Cell Nuclear Antigen

TCGA: The Cancer Genome Atlas

GSEA: Gene Set Enrichment Analysis

OS: Overall Survival

DFS: Disease-free Survival

PPI: Protein-protein Interaction

GO: Gene Ontology

KEGG: Kyoto Encyclopedia of Genes and Genomes

ATM: Ataxia Telangiectasia Mutated

CDK: Cyclin Dependent Kinase

ATR: Ataxia telangiectasia and Rad3 related

PLK: Polo Like Kinase

\section{Declarations}

Ethics approval and consent to participate: Not applicable.

Consent for publication: Not applicable. 
Availability of data and materials: The datasets generated and/or analysed during the current study are available in the public databases mentioned in Methods.

Competing interests: The authors declare that they have no competing interests.

Funding: None.

Author contributions:

Conception and design: Yuefeng Wang, Liyun Huo; Administrative support: Zunfu Ke; Provision of study materials or patients: Yuefeng Wang; Collection and assembly of data: Liyun Huo; Data analysis and interpretation: Yuefeng Wang; Manuscript writing: All authors; Final approval of manuscript: All authors.

Acknowledgments: None.

Author information:

Yuefeng Wang and Liyun Huo contributed equally to this work.

Correspondence to Zunfu Ke.

Affliations:

Yuefeng Wang and Zunfu Ke: Department of Pathology, the First Affiliated Hospital of Sun Yat-sen University, Guangzhou, Province Guangdong, P.R. China

Liyun Huo: Department of Hepatobiliary Surgery, Sun Yat-sen Memorial Hospital, Sun Yat-sen University, Guangzhou, Guangdong, People's Republic of China

\section{References}

1. Ostrom QT, Cioffi G, Gittleman H, Patil N, Waite K, Kruchko C, et al. CBTRUS Statistical Report: Primary Brain and Other Central Nervous System Tumors Diagnosed in the United States in 20122016. Neuro Oncol. 2019;21:v1-v100.

2. Louis DN, Ohgaki H, Wiestler O, Cavenee W, Burger P, Jouvet A, et al. The 2007 WHO classification of tumours of the central nervous system. Acta Neuropathol. 2007;114:97-109.

3. Kleihues P, Louis D, Scheithauer B, Rorke L, Reifenberger G, Burger P, et al. The WHO classification of tumors of the nervous system. J Neuropathol Exp Neurol. 2002;61:215-225.

4. Duffau $H$, Taillandier L. New concepts in the management of diffuse low-grade glioma: Proposal of a multistage and individualized therapeutic approach. Neuro Oncol. 2015;17:332-342.

5. Pallud J, Blonski M, Mandonnet E, Audureau E Fau - Fontaine D, Fontaine D Fau - Sanai N, Sanai N Fau - Bauchet L, et al. Velocity of tumor spontaneous expansion predicts long-term outcomes for diffuse low-grade gliomas. Neuro Oncol. 2013;15:595-606. 
6. Wang TJC, Mehta MP. Low-Grade Glioma Radiotherapy Treatment and Trials. Neurosurg Clin N Am. 2019;30:111-118.

7. Pallud J, Mandonnet E, Duffau H, Kujas M Fau - Guillevin R, Guillevin R Fau - Galanaud D, Galanaud D Fau - Taillandier $L$, et al. Prognostic value of initial magnetic resonance imaging growth rates for World Health Organization grade II gliomas. Ann Neurol. 2006;60:380-383.

8. Rueda E, Sierra M, Infante J, Berciano J Fau - Vázquez-Barquero A, Vázquez-Barquero A Fau - Ciordia $\mathrm{R}$, Ciordia R Fau - Martino J, et al. Controversial aspects in WHO grade II gliomas management: review of recent literature. Rev Neurol. 2011;53:747-757.

9. Wessels PH, Weber W, Raven G, Ramaekers Fc Fau - Hopman AHN, Hopman Ah Fau - Twijnstra A, Twijnstra A. Supratentorial grade II astrocytoma: biological features and clinical course. Lancet Neurol. 2003;2:395-403.

10. Tsurimoto T, Stillman B. Purification of a cellular replication factor, RF-C, that is required for coordinated synthesis of leading and lagging strands during simian virus 40 DNA replication in vitro. Mol Cell Biol. 1989;9:609-619.

11. Li Y, Gan S, Ren L, Yuan L, Liu J, Wang W, et al. Multifaceted regulation and functions of replication factor $C$ family in human cancers. Am J Cancer Res. 2018;8:1343-1355.

12. Szklarczyk D, Gable AL, Lyon D, Junge A, Wyder S, Huerta-Cepas J, et al. STRING v11: protein-protein association networks with increased coverage, supporting functional discovery in genome-wide experimental datasets. Nucleic Acids Res. 2019;47:D607-D613.

13. Maradeo ME, Garg A, Skibbens RV. Rfc5p regulates alternate RFC complex functions in sister chromatid pairing reactions in budding yeast. Cell Cycle. 2010;9:4370-4378.

14. Ata H, Shrestha D, Oka M, Ochi R Fau - Jong CJ, Jong Cj Fau - Gebb S, Gebb S Fau - Benjamin J, et al. Down-regulation of replication factor C-40 (RFC40) causes chromosomal missegregation in neonatal and hypertrophic adult rat cardiac myocytes. PLoS One. 2012;7:e39009.

15. Ellison V, Stillman B. Biochemical characterization of DNA damage checkpoint complexes: clamp loader and clamp complexes with specificity for 5' recessed DNA. PLoS Biol. 2003;1:E33.

16. Arai M, Kondoh N, Imazeki N, Hada A Fau - Hatsuse K, Hatsuse K Fau - Matsubara O, Matsubara 0 Fau - Yamamoto $M$, et al. The knockdown of endogenous replication factor $\mathrm{C} 4$ decreases the growth and enhances the chemosensitivity of hepatocellular carcinoma cells. Liver Int. 2009;29:55-62.

17. Kim YR, Song S, Kim S, An Ch Fau - Lee SH, Lee Sh Fau - Yoo NJ, Yoo NJ. Mutational and expressional analysis of RFC3, a clamp loader in DNA replication, in gastric and colorectal cancers. Hum Pathol. 2010;41:1431-1437.

18. Moggs JG, Murphy T, Lim F, Moore Dj Fau - Stuckey R, Stuckey R Fau - Antrobus K, Antrobus K Fau Kimber I, et al. Anti-proliferative effect of estrogen in breast cancer cells that re-express ERalpha is mediated by aberrant regulation of cell cycle genes. J Mol Endocrinol. 2005;34:535-551.

19. Xiong S, Wang Q, Zheng L, Gao F Fau - Li J, Li J. Identification of candidate molecular markers of nasopharyngeal carcinoma by tissue microarray and in situ hybridization. Med Oncol. 2011;Suppl 1:S341-348. 
20. Shen H, Cai M, Zhao S, Wang H Fau - Li M, Li M Fau - Yao S, Yao S Fau - Jiang N, et al. Overexpression of RFC3 is correlated with ovarian tumor development and poor prognosis. Tumour Biol. 2014;35:10259-10266.

21. Hatfield KJ, Reikvam H Fau - Bruserud $\varnothing$, Bruserud $\varnothing$. Identification of a subset of patients with acute myeloid leukemia characterized by long-term in vitro proliferation and altered cell cycle regulation of the leukemic cells. Expert Opin Ther Targets. 2014;18:1237-1251.

22. Lockwood WW, Thu K, Lin L, Pikor La Fau - Chari R, Chari R Fau - Lam WL, Lam WI Fau - Beer DG, et al. Integrative genomics identified RFC3 as an amplified candidate oncogene in esophageal adenocarcinoma. Clin Cancer Res. 2012;18:1936-1946.

23. Niu G, Wang D, Pei Y, Sun L. Systematic identification of key genes and pathways in the development of invasive cervical cancer. Gene. 2017;618:28-41.

24. Fatima A, Tariq F, Malik MFA, Qasim M, Haq F. Copy Number Profiling of MammaPrint ${ }^{\mathrm{TM}}$ Genes Reveals Association with the Prognosis of Breast Cancer Patients. J Breast Cancer. 2017;20:246-253.

25. Martinez I, Wang J, Hobson K, Ferris RI Fau - Khan SA, Khan SA. Identification of differentially expressed genes in HPV-positive and HPV-negative oropharyngeal squamous cell carcinomas. Eur $\mathrm{J}$ Cancer. 2007;43:415-432.

26. Almeida J, Costa J, Coelho P, Cea V, Galesio M, Noronha JP, et al. Adipocyte proteome and secretome influence inflammatory and hormone pathways in glioma. Metab Brain Dis. 2019;34:141-152.

27. Ho KH, Kuo TC, Lee YT, Chen PH, Shih CM, Cheng CH, et al. Xanthohumol regulates miR-4749-5pinhibited RFC2 signaling in enhancing temozolomide cytotoxicity to glioblastoma. Life Sci. 2020;254:117807.

28. Suzuki T, Maruno M, Wada K, Kagawa N Fau - Fujimoto Y, Fujimoto Y Fau - Hashimoto N, Hashimoto N Fau - Izumoto S, et al. Genetic analysis of human glioblastomas using a genomic microarray system. Brain Tumor Pathol. 2004;21:27-34.

29. Tang J, He D, Yang P, He J, Zhang YA-O. Genome-wide expression profiling of glioblastoma using a large combined cohort. Sci Rep. 2018;8:15104.

30. Yang Q, Wang R, Wei B, Peng C, Wang L, Hu G, et al. Gene and microRNA Signatures Are Associated with the Development and Survival of Glioblastoma Patients. DNA Cell Biol. 2019;38:688-699.

31. Rhodes DR, Yu J, Shanker K, Deshpande N Fau - Varambally R, Varambally R Fau - Ghosh D, Ghosh D Fau - Barrette T, et al. ONCOMINE: a cancer microarray database and integrated data-mining platform. Neoplasia. 2004;6:1-6.

32. Tang Z, Li C, Kang B, Gao G, Li C, Zhang Z. GEPIA: a web server for cancer and normal gene expression profiling and interactive analyses. Nucleic Acids Res. 2017;45:W98-W102.

33. Asplund A, Edqvist P, Schwenk J, Pontén F. Antibodies for profiling the human proteome-The Human Protein Atlas as a resource for cancer research. Proteomics. 2012;12:2067-2077.

34. Gao J, Aksoy B, Dogrusoz U, Dresdner G Fau - Gross B, Gross B Fau - Sumer So, Sumer So Fau - Sun $\mathrm{Y}$, et al. Integrative analysis of complex cancer genomics and clinical profiles using the cBioPortal. Sci Signal. 2013;6:pl1. 
35. Shannon P, Markiel A, Ozier O, Baliga Ns Fau - Wang JT, Wang Jt Fau - Ramage D, Ramage D Fau Amin N, et al. Cytoscape: a software environment for integrated models of biomolecular interaction networks. Genome Res. 2003;13:2498-2504.

36. Yu G, Wang L, Han Y, He QY. clusterProfiler: an R package for comparing biological themes among gene clusters. OMICS. 2012;15:284-287.

37. Walter W, Sánchez-Cabo F, Ricote M. GOplot: an R package for visually combining expression data with functional analysis. Bioinformatics. 2015;31:2912-2914.

38. Luo W, Brouwer C. Pathview: an R/Bioconductor package for pathway-based data integration and visualization. Bioinformatics. 2013;29:1830-1831.

39. Vasaikar SV, Straub P, Wang J, Zhang B. LinkedOmics: analyzing multi-omics data within and across 32 cancer types. Nucleic Acids Res. 2018;46:D956-D963.

40. Li T, Fan J, Wang B, Traugh N, Chen Q, Liu JS, et al. TIMER: A Web Server for Comprehensive Analysis of Tumor-Infiltrating Immune Cells. Cancer Res. 2017;77:e108-e110.

41. Pomeroy SL, Tamayo P, Gaasenbeek M, Sturla Lm Fau - Angelo M, Angelo M Fau - McLaughlin ME, McLaughlin Me Fau - Kim JYH, et al. Prediction of central nervous system embryonal tumour outcome based on gene expression. Nature. 2002;415:436-442.

42. Bredel M, Bredel C, Juric D, Harsh Gr Fau - Vogel H, Vogel H Fau - Recht LD, Recht Ld Fau - Sikic BI, et al. Functional network analysis reveals extended gliomagenesis pathway maps and three novel MYC-interacting genes in human gliomas. Cancer Res. 2005;65:8679-8689.

43. Sun L, Hui A, Su Q, Vortmeyer A Fau - Kotliarov Y, Kotliarov Y Fau - Pastorino S, Pastorino S Fau Passaniti A, et al. Neuronal and glioma-derived stem cell factor induces angiogenesis within the brain. Cancer Cell. 2006;9:287-300.

44. Murat A, Migliavacca E, Gorlia T, Lambiv WI Fau - Shay T, Shay T Fau - Hamou M-F, Hamou Mf Fau de Tribolet $\mathrm{N}$, et al. Stem cell-related "self-renewal" signature and high epidermal growth factor receptor expression associated with resistance to concomitant chemoradiotherapy in glioblastoma. J Clin Oncol. 2008;26:3015-3024.

45. Liang Y, Diehn M, Watson N, Bollen Aw Fau - Aldape KD, Aldape Kd Fau - Nicholas MK, Nicholas Mk Fau - Lamborn KR, et al. Gene expression profiling reveals molecularly and clinically distinct subtypes of glioblastoma multiforme. Proc Natl Acad Sci USA. 2005;102:5814-5819.

46. French PJ, Swagemakers S, Nagel J, Kouwenhoven Mc Fau - Brouwer E, Brouwer E Fau - van der Spek P, van der Spek P Fau - Luider TM, et al. Gene expression profiles associated with treatment response in oligodendrogliomas. Cancer Res. 2005;65:11335-11344.

47. Peng WX, Han X, Zhang CL, Ge L, Du FY, Jin J, et al. FoxM1-mediated RFC5 expression promotes temozolomide resistance. Cell Biol Toxicol. 2017;33:527-537.

48. Okumura K, Nogami M, Taguchi H, Dean Fb Fau - Chen M, Chen M Fau - Pan ZQ, Pan Zq Fau Hurwitz J, et al. Assignment of the 36.5-kDa (RFC5), 37-kDa (RFC4), 38-kDa (RFC3), and 40-kDa (RFC2) subunit genes of human replication factor $C$ to chromosome bands 12q24.2-q24.3, 3q27, 13q12.3-q13, and 7q11.23. Genomics. 1995;25:274-278. 
49. Zhou W, Sun M, Li G, Wu Yz Fau - Wang Y, Wang Y Fau - Jin F, Jin F Fau - Zhang Y-Y, et al. Activation of the phosphorylation of ATM contributes to radioresistance of glioma stem cells. Oncol Rep. 2013;30:1793-1801.

50. Wang J, Li B, Wang C, Luo Y, Zhao M, Chen PA-OX. Long noncoding RNA FOXD2-AS1 promotes glioma cell cycle progression and proliferation through the FOXD2-AS1/miR-31/CDK1 pathway. J Cell Biochem. 2019;120:19784-19795.

51. Li Y, Li L, Wu Z, Wang L, Wu Y, Li D, et al. Silencing of ATM expression by siRNA technique contributes to glioma stem cell radiosensitivity in vitro and in vivo. Oncol Rep. 2017;38:325-335.

52. Hu T, Shen H, Li J, Yang P, Gu Q, Fu ZA-O. RFC2, a direct target of miR-744, modulates the cell cycle and promotes the proliferation of CRC cells. J Cell Physiol. 2020;235:8319-8333.

53. Xu J, Wang G, Gong W, Guo S, Li D, Zhan QA-OX. The noncoding function of NELFA mRNA promotes the development of oesophageal squamous cell carcinoma by regulating the Rad17-RFC2-5 complex. Mol Oncol. 2020;14:611-624.

54. Nakahara Y, Shiraishi T, Okamoto H, Mineta T Fau - Oishi T, Oishi T Fau - Sasaki K, Sasaki K Fau Tabuchi K, et al. Detrended fluctuation analysis of genome-wide copy number profiles of glioblastomas using array-based comparative genomic hybridization. Neuro Oncol. 2004;6:281-289.

55. Saldivar JC, Cortez D, Cimprich KA. The essential kinase ATR: ensuring faithful duplication of a challenging genome. Nat Rev Mol Cell Biol. 2017;18:622-636.

56. Krajewska M, Fehrmann RS, Schoonen PM, Labib S, de Vries EG, Franke L, et al. ATR inhibition preferentially targets homologous recombination-deficient tumor cells. Oncogene. 2015;34:34743481.

57. Gong S, Qu X, Yang S, Zhou S, Li P, Zhang Q. RFC3 induces epithelial-mesenchymal transition in lung adenocarcinoma cells through the Wnt/ $\beta$-catenin pathway and possesses prognostic value in lung adenocarcinoma. Int J Mol Med. 2019;44:2276-2288.

58. Chae HD, Mitton B, Lacayo NJ, Sakamoto KM. Replication factor C3 is a CREB target gene that regulates cell cycle progression through the modulation of chromatin loading of PCNA. Leukemia. 2015;29:1379-1389.

59. Bachtiary B, Boutros P, Pintilie M, Shi W Fau - Bastianutto C, Bastianutto C Fau - Li J-H, Li Jh Fau Schwock J, et al. Gene expression profiling in cervical cancer: an exploration of intratumor heterogeneity. Clin Cancer Res. 2006;12:5632-5640.

60. Varghese S, Xu H, Bartlett D, Hughes M Fau - Pingpank JF, Pingpank Jf Fau - Beresnev T, Beresnev T Fau - Alexander HR, Jr., et al. Isolated hepatic perfusion with high-dose melphalan results in immediate alterations in tumor gene expression in patients with metastatic ocular melanoma. Ann Surg Oncol. 2010;17:1870-1877.

61. Wang M, Xie T, Wu Y, Yin Q, Xie S, Yao Q, et al. Identification of RFC5 as a novel potential prognostic biomarker in lung cancer through bioinformatics analysis. Oncol Lett. 2018;16:4201-4210.

\section{Tables}


Table 01. The Significant Changes of RFC Expression in Transcription Level between Brain and Central Nervous System (CNS) Cancer and Normal Tissues (ONCOMINE Database)

\begin{tabular}{|c|c|c|c|c|c|}
\hline & $\begin{array}{l}\text { Type of Brain and CNS Cancer VS. } \\
\text { Normal }\end{array}$ & $\begin{array}{l}\text { Fold } \\
\text { Change }\end{array}$ & $\stackrel{\mathrm{p}}{\text { Value }}$ & t Test & $\begin{array}{l}\text { Source and/or } \\
\text { Reference }\end{array}$ \\
\hline \multirow[t]{2}{*}{ RFC1 } & $\begin{array}{l}\text { Desmoplastic Medulloblastoma vs. } \\
\text { Normal }\end{array}$ & 1.894 & $\begin{array}{l}2.00 \mathrm{E}- \\
03\end{array}$ & 3.988 & Pomeroy Brain \\
\hline & Glioblastoma vs. Normal & 1.594 & $\begin{array}{l}1.00 \mathrm{E}- \\
03\end{array}$ & 4.722 & TCGA Brain \\
\hline \multirow[t]{7}{*}{ RFC2 } & Glioblastoma vs. Normal & 1.769 & $\begin{array}{l}4.49 \mathrm{E}- \\
08\end{array}$ & 7.695 & Bredel Brain 2 \\
\hline & $\begin{array}{l}\text { Anaplastic Oligodendroglioma vs. } \\
\text { Normal }\end{array}$ & 1.554 & $\begin{array}{l}3.48 \mathrm{E}- \\
4\end{array}$ & 7.94 & Bredel Brain 2 \\
\hline & Glioblastoma vs. Normal & 1.679 & $\begin{array}{l}1.50 \mathrm{E}- \\
15\end{array}$ & 9.364 & Sun Brain \\
\hline & $\begin{array}{l}\text { Anaplastic Oligodendroglioma vs. } \\
\text { Normal }\end{array}$ & 1.708 & $\begin{array}{l}4.91 \mathrm{E}- \\
06\end{array}$ & 5.795 & French Brain \\
\hline & Glioblastoma vs. Normal & 1.706 & $\begin{array}{l}2.00 \mathrm{E}- \\
03\end{array}$ & 4.417 & TCGA Brain \\
\hline & Brain Glioblastoma vs. Normal & 2.667 & $\begin{array}{l}6.65 \mathrm{E}- \\
09\end{array}$ & 15.075 & TCGA Brain \\
\hline & Glioblastoma vs. Normal & 1.719 & $\begin{array}{l}2.11 \mathrm{E}- \\
05\end{array}$ & 8.573 & Murat Brain \\
\hline \multirow[t]{5}{*}{ RFC3 } & Glioblastoma vs. Normal & 1.617 & $\begin{array}{l}1.54 \mathrm{E}- \\
10\end{array}$ & 9.599 & Liang Brain \\
\hline & $\begin{array}{l}\text { Anaplastic Oligoastrocytoma vs. } \\
\text { Normal }\end{array}$ & 3.709 & $\begin{array}{l}1.61 \mathrm{E}- \\
04\end{array}$ & 6.85 & French Brain \\
\hline & $\begin{array}{l}\text { Anaplastic Oligodendroglioma vs. } \\
\text { Normal }\end{array}$ & 2.454 & $\begin{array}{l}3.57 \mathrm{E}- \\
05\end{array}$ & 5.372 & French Brain \\
\hline & $\begin{array}{l}\text { Anaplastic Oligodendroglioma vs. } \\
\text { Normal }\end{array}$ & 2.024 & $\begin{array}{l}8.00 \mathrm{E}- \\
03\end{array}$ & 7.575 & Bredel Brain 2 \\
\hline & Oligodendroglioma vs. Normal & 1.781 & $\begin{array}{l}1.80 \mathrm{E}- \\
02\end{array}$ & 3.121 & Bredel Brain 2 \\
\hline RFC4 & $\begin{array}{l}\text { Anaplastic Oligodendroglioma vs. } \\
\text { Normal }\end{array}$ & 2.293 & $\begin{array}{l}7.94 \mathrm{E}- \\
09\end{array}$ & 8.036 & French Brain \\
\hline & Glioblastoma vs. Normal & 2.572 & $\begin{array}{l}5.52 \mathrm{E}- \\
10\end{array}$ & 12.701 & Murat Brain \\
\hline & Glioblastoma vs. Normal & 1.634 & $\begin{array}{l}9.02 \mathrm{E}- \\
05\end{array}$ & 4.97 & Bredel Brain 2 \\
\hline & Glioblastoma vs. Normal & 1.75 & $5.91 \mathrm{E}-$ & 7.504 & Sun Brain \\
\hline
\end{tabular}




\begin{tabular}{|c|c|c|c|c|c|}
\hline & Anaplastic Astrocytoma vs. Normal & 1.543 & $\begin{array}{l}4.51 \mathrm{E}- \\
05\end{array}$ & 4.496 & Sun Brain \\
\hline & Oligoastrocytoma vs. Normal & 1.753 & $\begin{array}{l}5.00 \mathrm{E}- \\
03\end{array}$ & 5.3 & Liang Brain \\
\hline & Glioblastoma vs. Normal & 1.813 & $\begin{array}{l}2.00 \mathrm{E}- \\
03\end{array}$ & 5.188 & Liang Brain \\
\hline \multirow[t]{8}{*}{ RFC5 } & Glioblastoma vs. Normal & 1.8 & $\begin{array}{l}9.31 \mathrm{E}- \\
15\end{array}$ & 9.773 & Sun Brain \\
\hline & Anaplastic Astrocytoma vs. Normal & 1.799 & $\begin{array}{l}1.30 \mathrm{E}- \\
06\end{array}$ & 5.956 & Sun Brain \\
\hline & Oligodendroglioma vs. Normal & 1.6 & $\begin{array}{l}2.78 \mathrm{E}- \\
08\end{array}$ & 6.074 & Sun Brain \\
\hline & $\begin{array}{l}\text { Anaplastic Oligodendroglioma vs. } \\
\text { Normal }\end{array}$ & 1.831 & $\begin{array}{l}8.57 \mathrm{E}- \\
6\end{array}$ & 6.498 & French Brain \\
\hline & $\begin{array}{l}\text { Anaplastic Oligoastrocytoma vs. } \\
\text { Normal }\end{array}$ & 2.51 & $\begin{array}{l}3.00 \mathrm{E}- \\
03\end{array}$ & 4.453 & French Brain \\
\hline & Glioblastoma vs. Normal & 2.436 & $\begin{array}{l}2.88 \mathrm{E}- \\
06\end{array}$ & 11.406 & Murat Brain \\
\hline & $\begin{array}{l}\text { Desmoplastic Medulloblastoma } \\
\text { vs.Normal }\end{array}$ & 1.894 & $\begin{array}{l}2.00 \mathrm{E}- \\
03\end{array}$ & 3.988 & Pomeroy Brain \\
\hline & Brain Glioblastoma vs. Normal & 3.683 & $\begin{array}{l}2.55 \mathrm{E}- \\
08\end{array}$ & 14.125 & TCGA Brain \\
\hline
\end{tabular}


Table 02. The Kinases, miRNAs and transcription factors-target networks of SMCs in LIHC (Linkedomics)

\begin{tabular}{|c|c|c|c|c|c|c|}
\hline $\begin{array}{l}\text { Enriched } \\
\text { Category }\end{array}$ & RFCs & Geneset & $\begin{array}{l}\text { Leading } \\
\text { Edge } \\
\text { Number }\end{array}$ & $\begin{array}{l}\text { Normalized } \\
\text { Enrichment } \\
\text { Score }\end{array}$ & $\begin{array}{l}\mathrm{P} \text { - } \\
\text { value }\end{array}$ & FDR \\
\hline \multirow{10}{*}{$\begin{array}{l}\text { Kinase } \\
\text { Target }\end{array}$} & RFC1 & Kinase_ATM & 51 & 2.058 & 0 & 0 \\
\hline & & Kinase_CDK1 & 118 & 1.832 & 0 & 0.003 \\
\hline & RFC2 & Kinase_ATR & 28 & 2.199 & 0 & 0 \\
\hline & & Kinase_PLK1 & 33 & 2.138 & 0 & 0 \\
\hline & RFC3 & Kinase_PLK1 & 35 & 2.087 & 0 & 0 \\
\hline & & Kinase_CDK1 & 97 & 2.052 & 0 & 0 \\
\hline & RFC4 & Kinase_PLK1 & 37 & 2.107 & 0 & 0 \\
\hline & & Kinase_ATR & 40 & 2.081 & 0 & 0 \\
\hline & RFC5 & Kinase_ATM & 57 & 2.079 & 0 & 0 \\
\hline & & Kinase_ATR & 35 & 2.078 & 0 & 0 \\
\hline \multirow{10}{*}{$\begin{array}{l}\text { miRNA } \\
\text { Target }\end{array}$} & RFC1 & ATACTGT,MIR-144 & 76 & 2.030 & 0 & 0 \\
\hline & & CTTGTAT,MIR-381 & 88 & 2.021 & 0 & 0 \\
\hline & RFC2 & $\begin{array}{l}\text { GCGCTTT,MIR- } \\
\text { 518B,MIR-518C,MIR- } \\
\text { 518D }\end{array}$ & 6 & 1.074 & 0.346 & 1 \\
\hline & & CGCTGCT,MIR-503 & 2 & 1.026 & 0.439 & 0.821 \\
\hline & RFC3 & ACCATTT,MIR-552 & 55 & 1.630 & 0 & 0.133 \\
\hline & & ATGCAGT,MIR-217 & 37 & 1.549 & 0.002 & 0.217 \\
\hline & RFC4 & CGCTGCT,MIR-503 & 7 & 1.251 & 0.15 & 1 \\
\hline & & CCAGGTT,MIR-490 & 26 & 1.072 & 0.357 & 1 \\
\hline & RFC5 & ATACTGT,MIR-144 & 64 & 1.729 & 0 & 0.052 \\
\hline & & ATGTCAC,MIR-489 & 17 & 1.623 & 0 & 0.134 \\
\hline \multirow{3}{*}{$\begin{array}{l}\text { Transcription } \\
\text { Factor }\end{array}$} & RFC1 & V\$E2F_Q4 & 87 & 1.898 & 0 & 0.001 \\
\hline & & V\$E2F_Q6 & 86 & 1.883 & 0 & 0.001 \\
\hline & RFC2 & VSE2F_Q3 & 58 & 2.068 & 0 & 0 \\
\hline
\end{tabular}




\begin{tabular}{clllll|} 
& V\$E2F_Q6 & 64 & 2.019 & 0 & 0 \\
RFC3 & V\$E2F1_Q6 & 89 & 2.125 & 0 & 0 \\
\cline { 2 - 3 } & V\$E2F_Q4 & 85 & 2.115 & 0 & 0 \\
RFC4 & V\$E2F4DP1_01 & 84 & 2.129 & 0 & 0 \\
\cline { 2 - 3 } & V\$E2F1_Q6 & 83 & 2.122 & 0 & 0 \\
RFC5 & V\$E2F_Q6 & 93 & 2.224 & 0 & 0 \\
& V\$E2F1_Q6 & 100 & 2.215 & 0 & 0 \\
\hline
\end{tabular}

Table 03. The cox proportional hazard model of RFCs and six tumor-infiltrating immune cells in LGG (TIMER)

\begin{tabular}{|c|c|c|c|c|c|c|}
\hline & coef & $\mathrm{HR}$ & 95\%Cl_I & 95\%Cl_u & p.value & sig \\
\hline B_cell & -1.638 & 0.194 & 0.001 & 57.521 & 0.573 & \\
\hline CD8_Tcell & 5.848 & 346.569 & 0.394 & 304734.350 & 0.091 & \\
\hline CD4_Tcell & 2.658 & 14.261 & 0.004 & 46459.439 & 0.520 & \\
\hline Macrophage & 5.431 & 228.295 & 3.716 & 14025.058 & 0.010 & * \\
\hline Neutrophil & -6.624 & 0.001 & 0.000 & 3.650 & 0.101 & \\
\hline Dentritic & 0.076 & 1.079 & 0.021 & 56.185 & 0.970 & \\
\hline RFC1 & -0.019 & 0.981 & 0.565 & 1.702 & 0.945 & \\
\hline RFC2 & 1.297 & 3.658 & 1.997 & 6.701 & 0.000 & $\star \star \star *$ \\
\hline RFC3 & 0.447 & 1.564 & 0.915 & 2.674 & 0.102 & \\
\hline RFC4 & -0.787 & 0.455 & 0.261 & 0.795 & 0.006 & $\star \star$ \\
\hline RFC5 & 0.139 & 1.149 & 0.776 & 1.701 & 0.488 & \\
\hline
\end{tabular}

Figures 


\begin{tabular}{|c|c|c|c|c|c|c|c|c|c|c|}
\hline \multirow{2}{*}{\begin{tabular}{|} 
Analysis Type by Cancer \\
Bladder Cancer
\end{tabular}} & \multicolumn{2}{|c|}{$\begin{array}{l}\text { Cancer } \\
\text { vs. } \\
\text { Normal } \\
\text { RFC1 }\end{array}$} & \multicolumn{2}{|c|}{$\begin{array}{c}\text { Cancer } \\
\text { vs. } \\
\text { Normal } \\
\text { RFC2 }\end{array}$} & \multicolumn{2}{|c|}{$\begin{array}{l}\text { Cancer } \\
\text { vs. } \\
\text { Normal } \\
\text { RFC3 }\end{array}$} & \multicolumn{2}{|c|}{$\begin{array}{c}\text { Cancer } \\
\text { vs. } \\
\text { Normal } \\
\text { RFC4 }\end{array}$} & \multicolumn{2}{|c|}{$\begin{array}{l}\text { Cancer } \\
\text { vs. } \\
\text { Normal } \\
\text { RFC5 }\end{array}$} \\
\hline & & & & & 1 & & 4 & & 3 & \\
\hline Brain and CNS Cancer & 2 & 2 & 7 & 1 & 5 & 1 & 7 & & 8 & 4 \\
\hline Breast Cancer & 2 & & 12 & 1 & 1 & 1 & 12 & 1 & 4 & \\
\hline Cervical Cancer & 1 & & 1 & & 3 & & 5 & & 4 & \\
\hline Colorectal Cancer & 1 & & 4 & & 20 & 1 & 14 & & 6 & \\
\hline Esophageal Cancer & 1 & 1 & & 1 & 3 & & 4 & & 2 & \\
\hline Gastric Cancer & & & 4 & & 10 & & 5 & & 5 & \\
\hline Head and Neck Cancer & & 1 & 5 & & 4 & & 9 & & 8 & \\
\hline Kidney Cancer & & & 4 & & 2 & & 2 & & 3 & \\
\hline Leukemia & 2 & 1 & & 2 & 3 & 5 & 1 & 1 & & 5 \\
\hline Liver Cancer & 4 & & 1 & & 2 & & 3 & & 2 & 1 \\
\hline Lung Cancer & & 1 & 7 & & 8 & & 14 & & 7 & \\
\hline Lymphoma & 1 & 5 & & 1 & 5 & & 4 & & 3 & 3 \\
\hline Melanoma & & & & & 1 & & 3 & & & \\
\hline Myeloma & 1 & & 2 & 1 & & & 1 & & 1 & \\
\hline Other Cancer & 4 & 8 & 5 & & 4 & & 4 & 1 & 13 & \\
\hline Ovarian Cancer & & 2 & 2 & & 1 & & 3 & & 2 & \\
\hline Pancreatic Cancer & 2 & 3 & & 1 & 2 & & & & & \\
\hline Prostate Cancer & 1 & & 1 & & 2 & 1 & 2 & & 4 & 1 \\
\hline Sarcoma & 5 & & 3 & & 11 & & 12 & & 10 & \\
\hline Significant Unique Analyses & 27 & 24 & 58 & 8 & 86 & 9 & 108 & 3 & 84 & 14 \\
\hline Total Unique Analyses & & & & & & & 40 & & & 4 \\
\hline
\end{tabular}

\section{Figure 1}

Transcription expression of RFCs in different types of cancers. The statistical analyzing method was Students' t-test. Cut-off of $p$ value was 0.05 , fold change was 1.5 , gene rank was $10 \%$, data type was mRNA. 
A
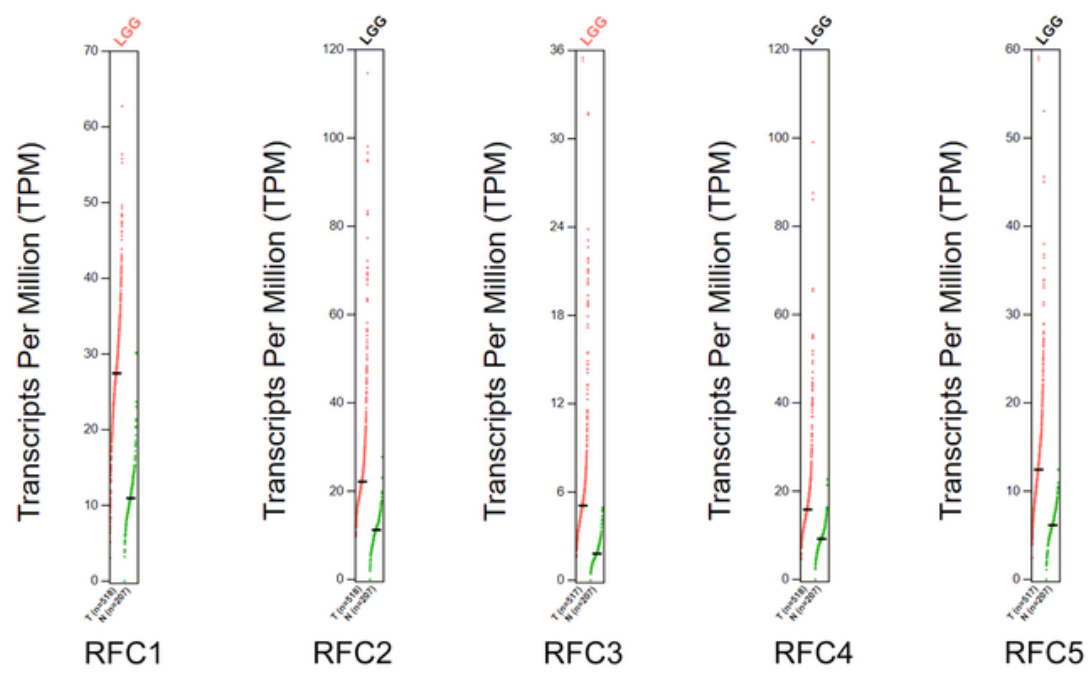

B
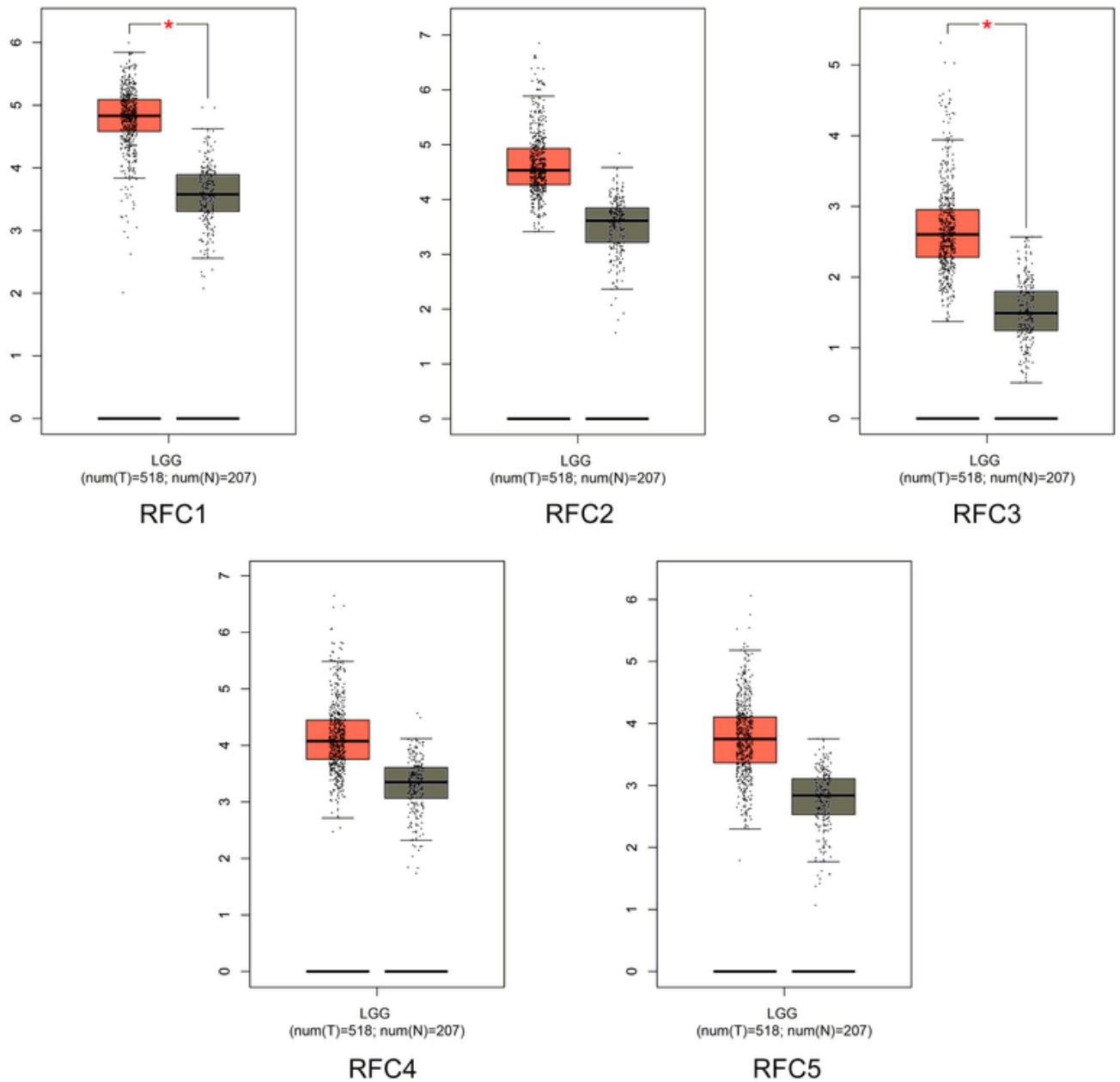

Figure 2

The expression profiles of RFCs in low-grade glioma. The mRNA level of RFCs in low-glioma. (A) Scatter diagram. (B) Box plot. 

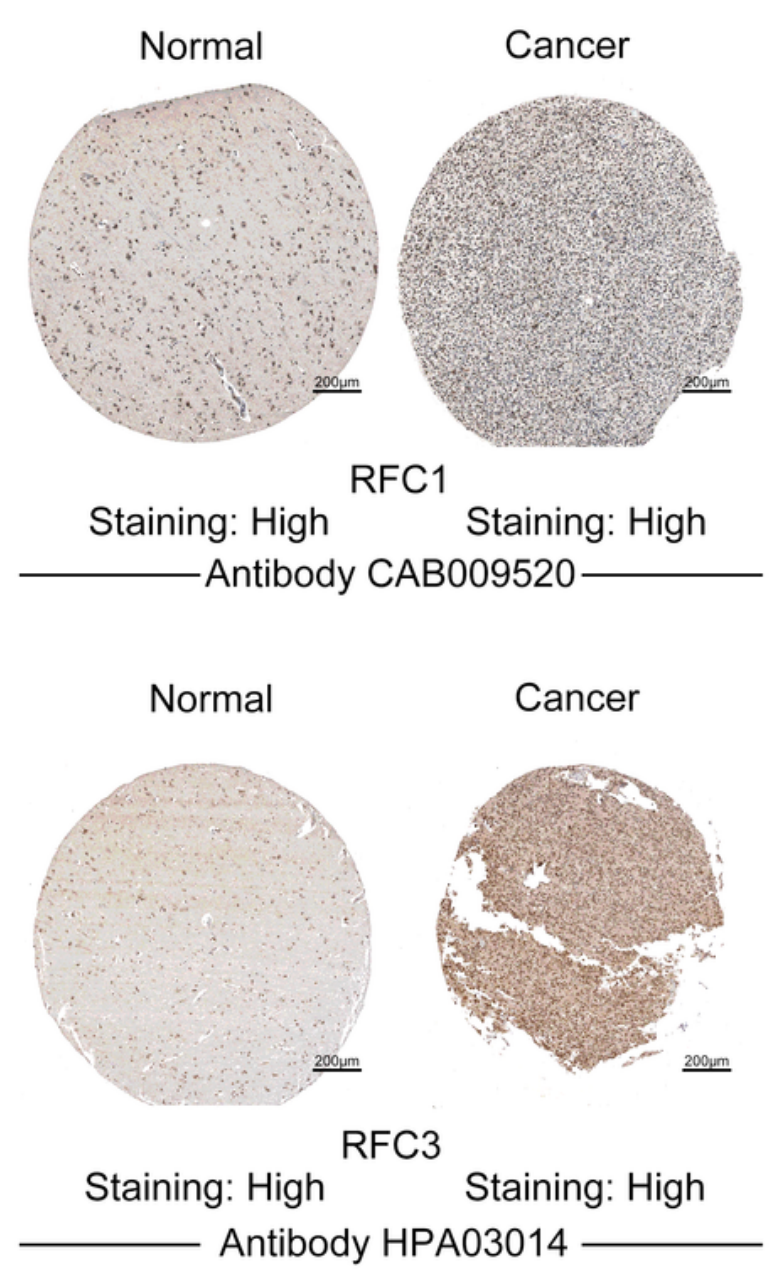
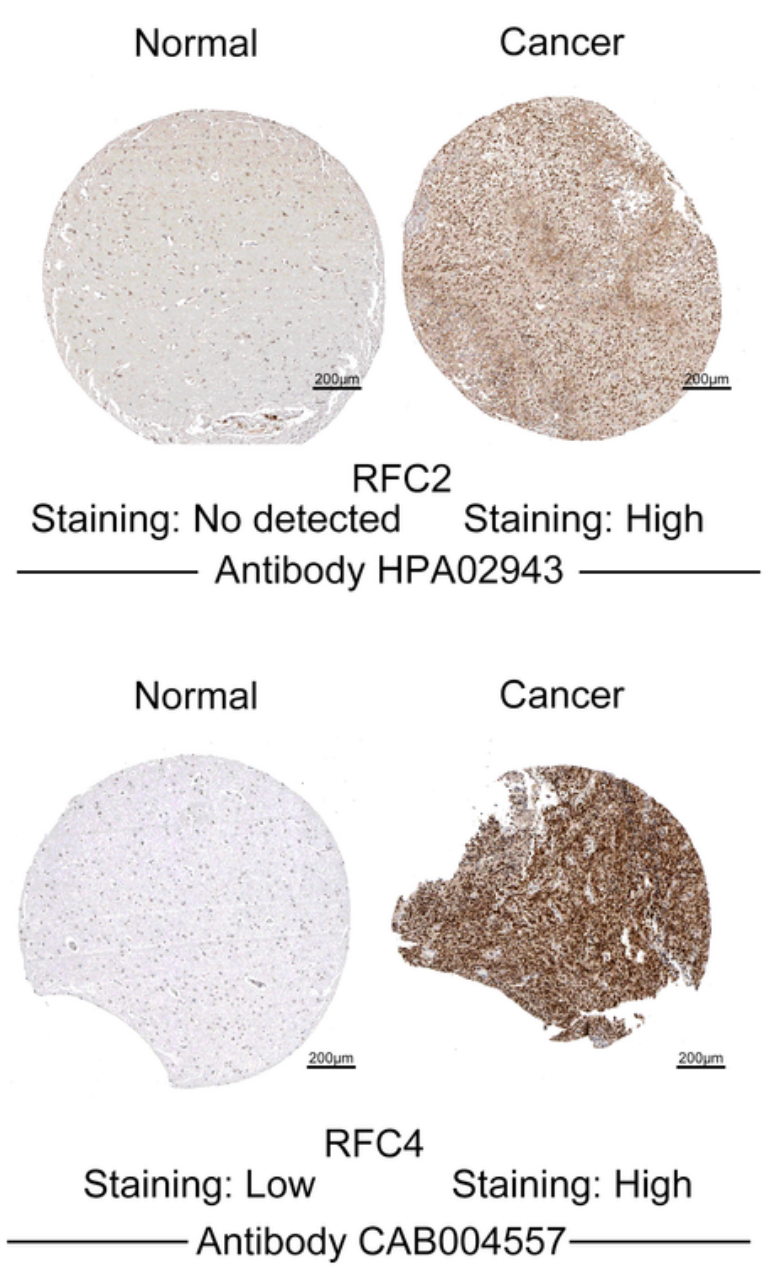

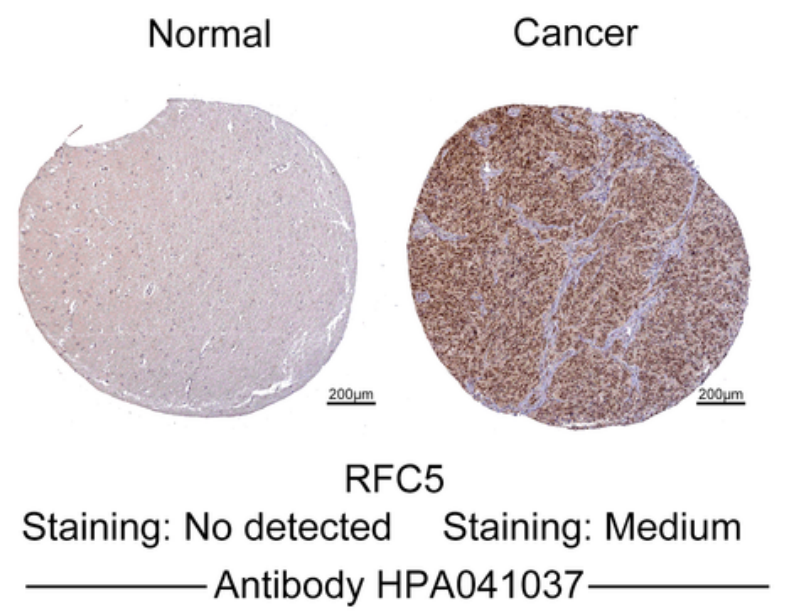

\section{Figure 3}

Representative immunohistochemistry images of RFCs gene family in glioma tissues and normal brain tissues. Scale bars: $200 \mu \mathrm{m}$. 
A

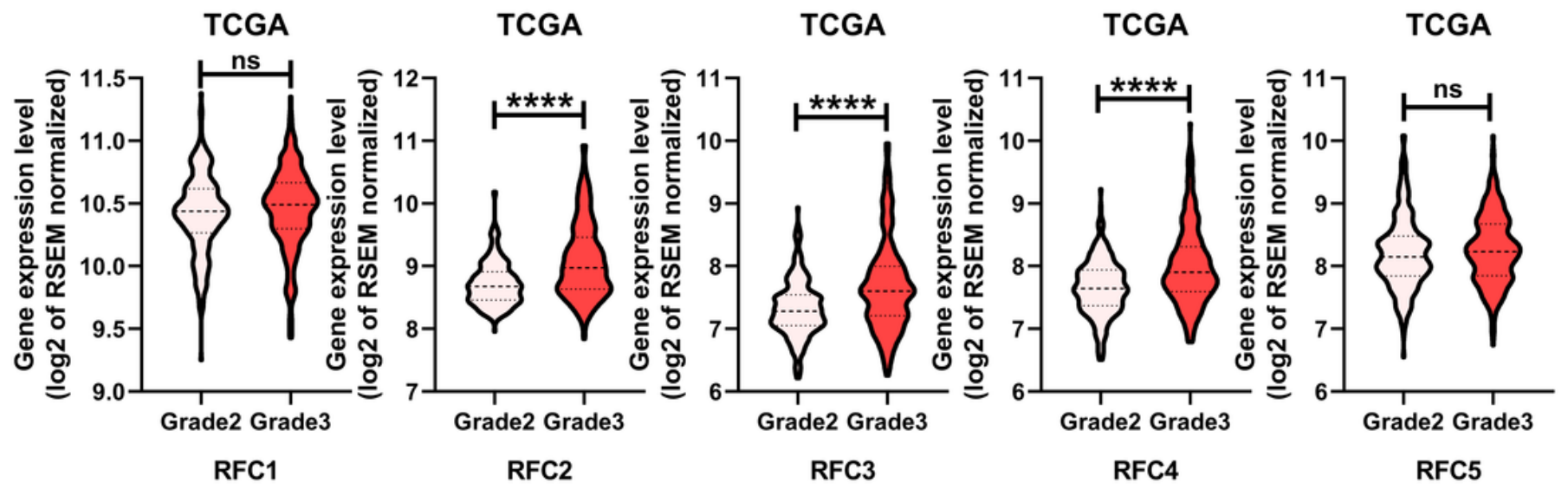

B

Sun Brain

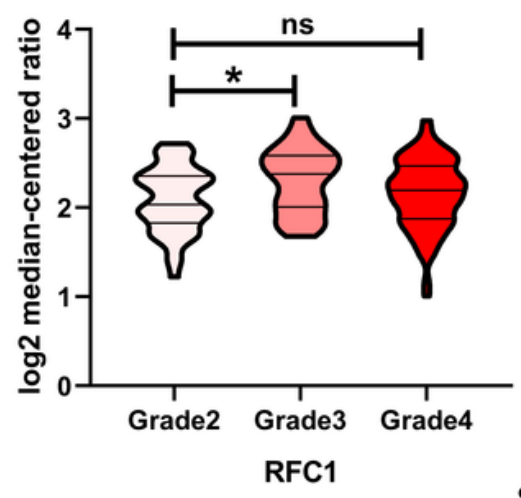

Sun Brain

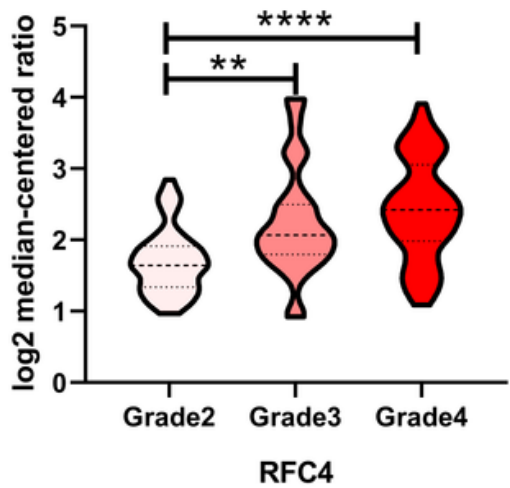

Sun Brain

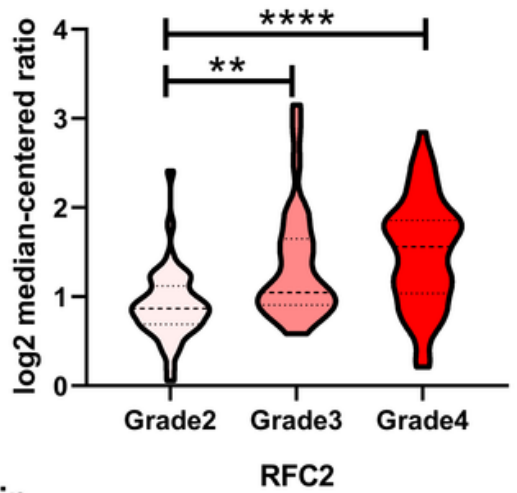

RFC2
Sun Brain

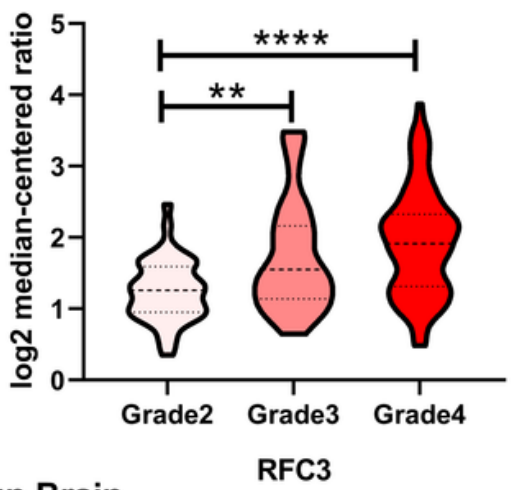

Sun Brain

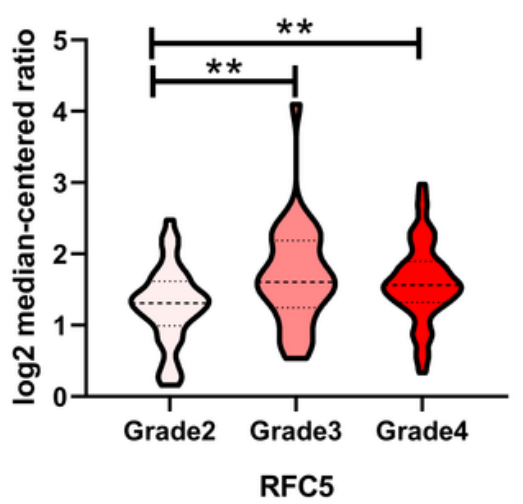

Figure 4

The correlation between RFCs expression levels and tumor grade in LGG and brain tumors. (A) The expression level of RFCs in different grades of LGG in TCGA datasets. (B) The expression level of RFCs in different grades of brain tumors in Sun Brain datasets. 
RFC1
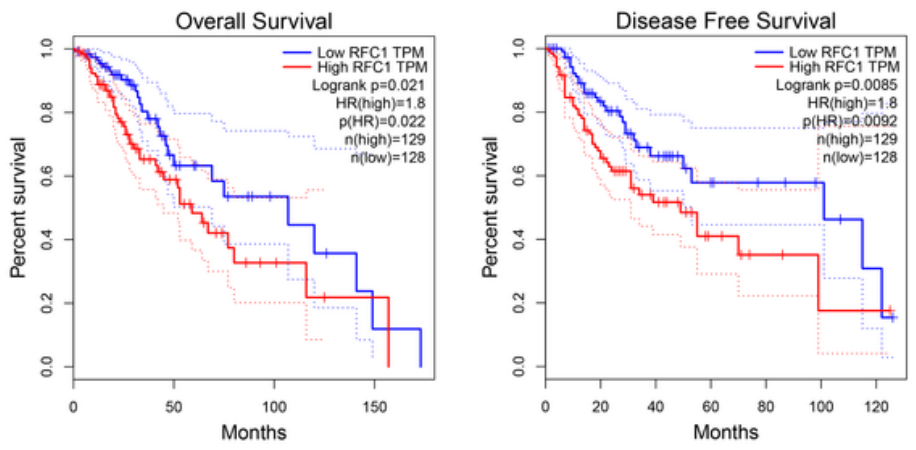

RFC3
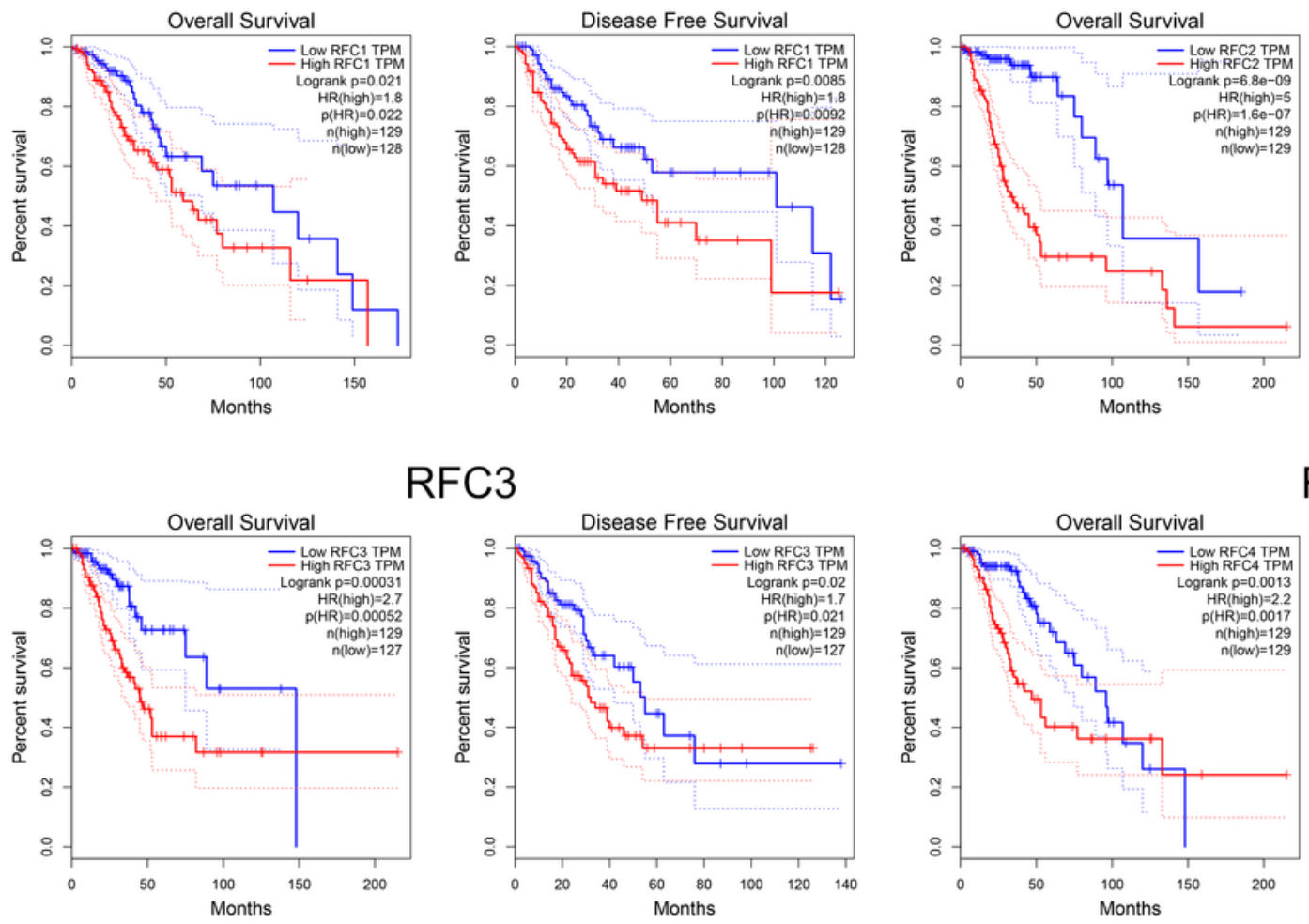

RFC2

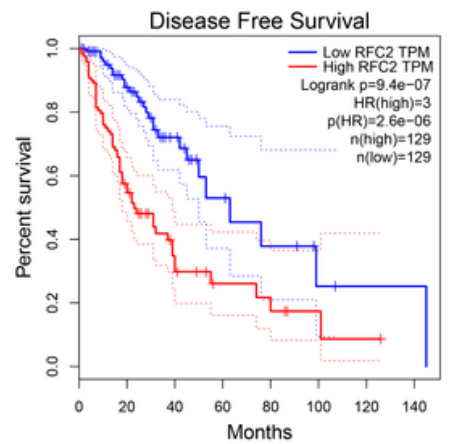

\section{RFC4}

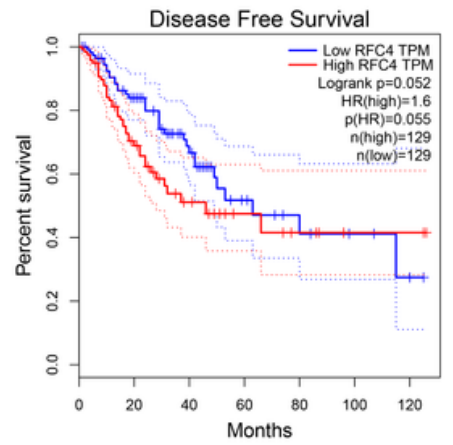

\section{RFC5}
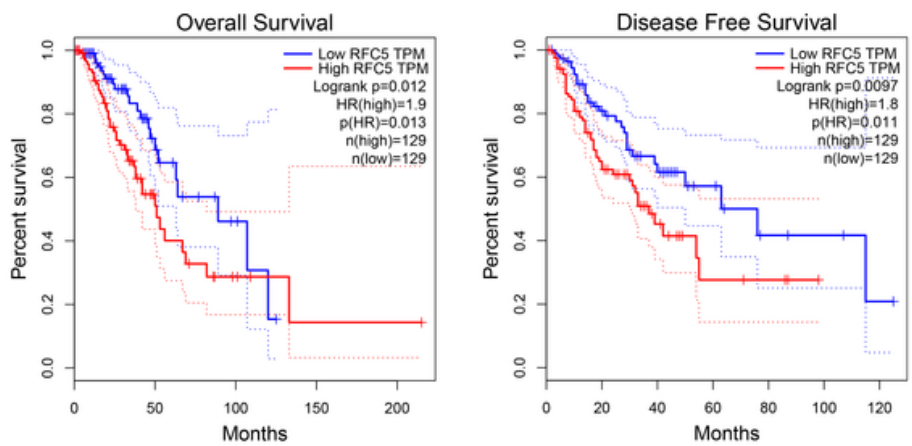

Figure 5

The prognostic value of mRNA expression of RFCs in low-grade glioma. Higher levels of RFCs were significantly associated with shorter OS of low-grade glioma patients. Higher levels of RFC1/2/3/5 were significantly associated with shorter DFS of low-grade glioma patients. The p value was set at 0.05 . 


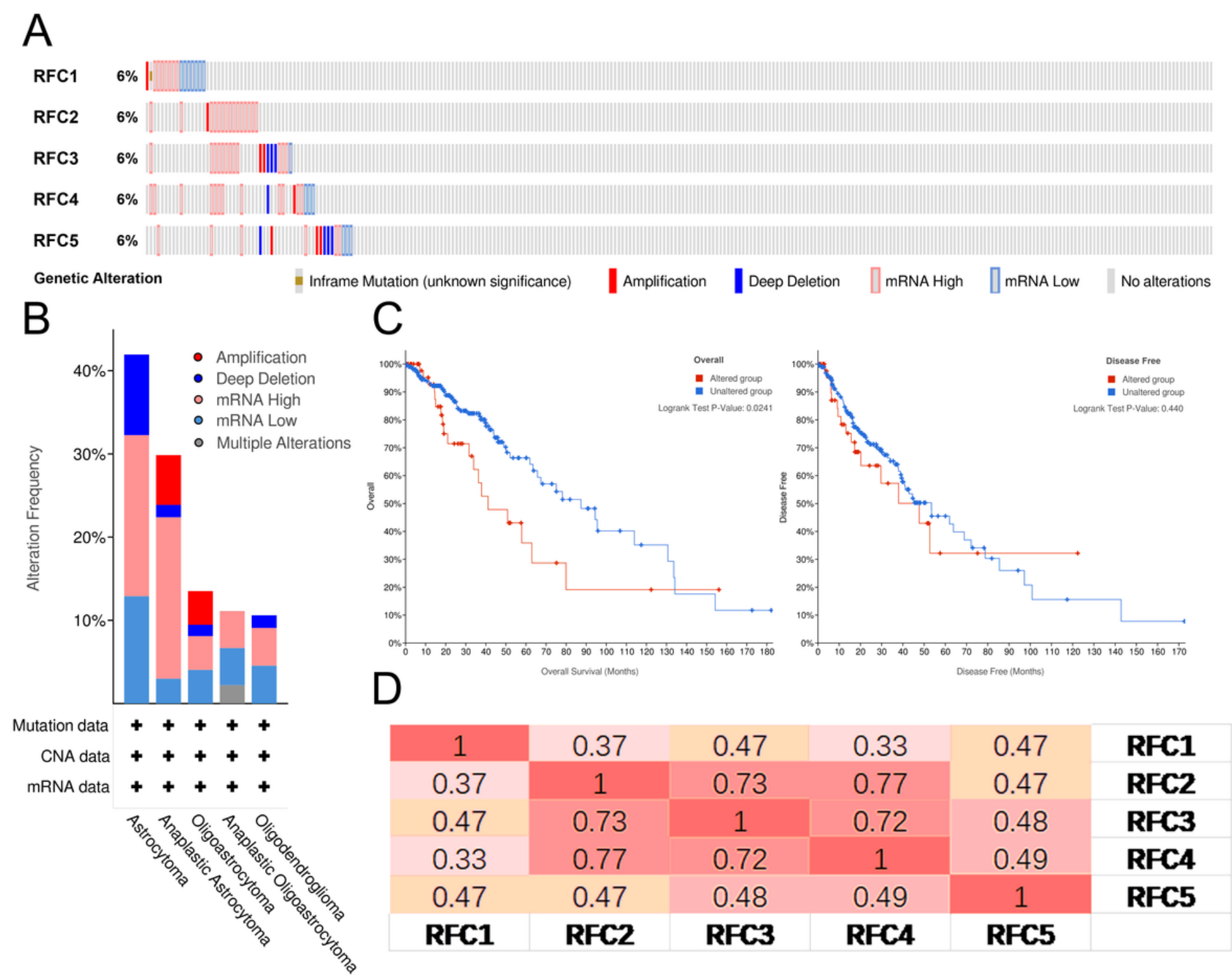

Figure 6

RFCs gene expression and mutation analysis in low-grade glioma. (A, B) RFCs gene expression and mutation analysis in low-grade glioma (cBioPortal). (C) The OS and DFS curves of mutated RFCs genes. (D) Correlation between different RFCs in low-grade glioma (GEPIA). 

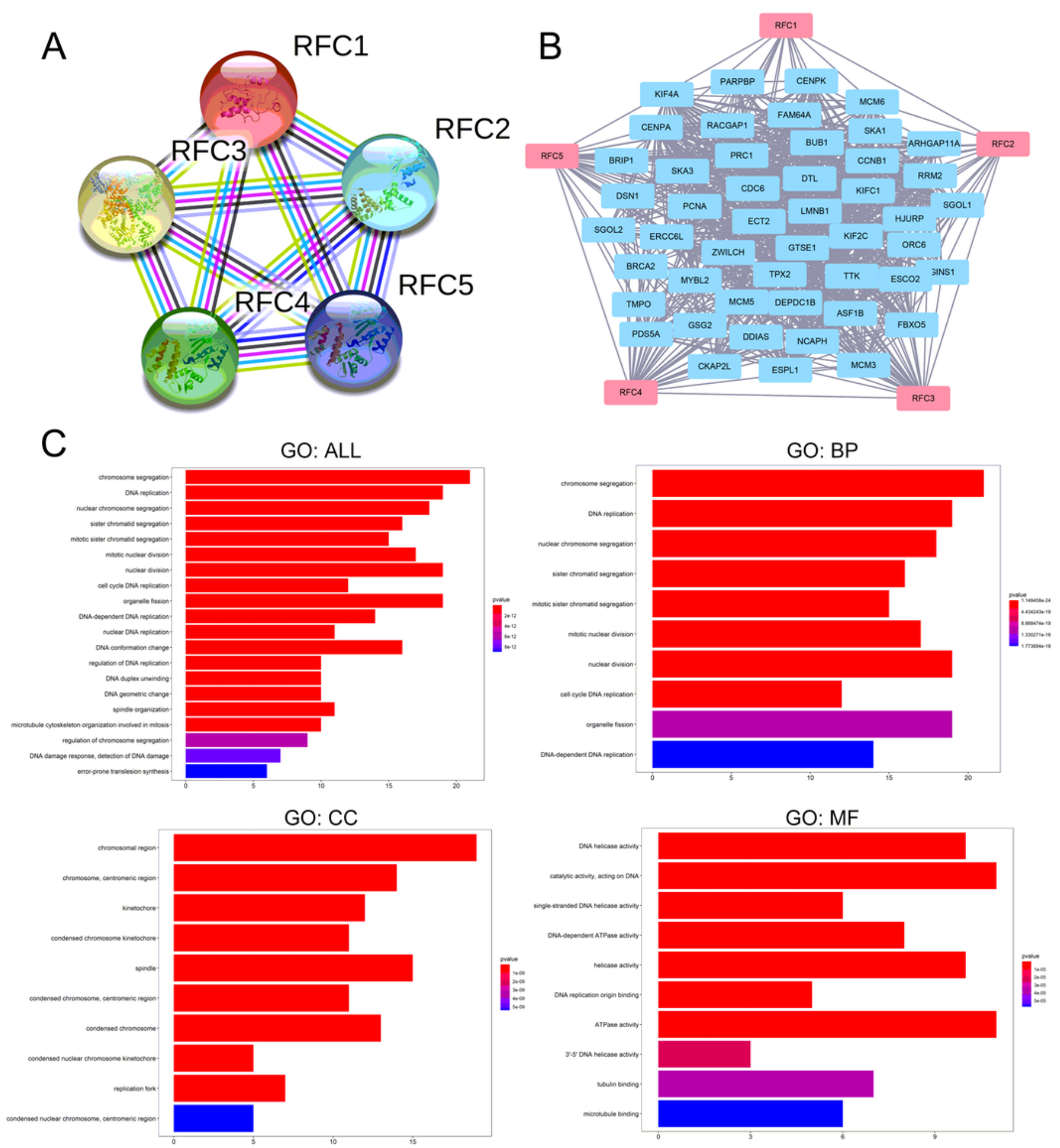

\section{Figure 7}

The PPI network and GO enrichment of RFCs and 50 frequently altered neighbor genes. (A, B) The PPI network of RFCs and 50 frequently altered neighbor genes. (C) GO functional enrichment analysis of RFCs and their 50 frequently altered neighbor genes, biological process, cellular components and molecular functions analysis were included. 
A

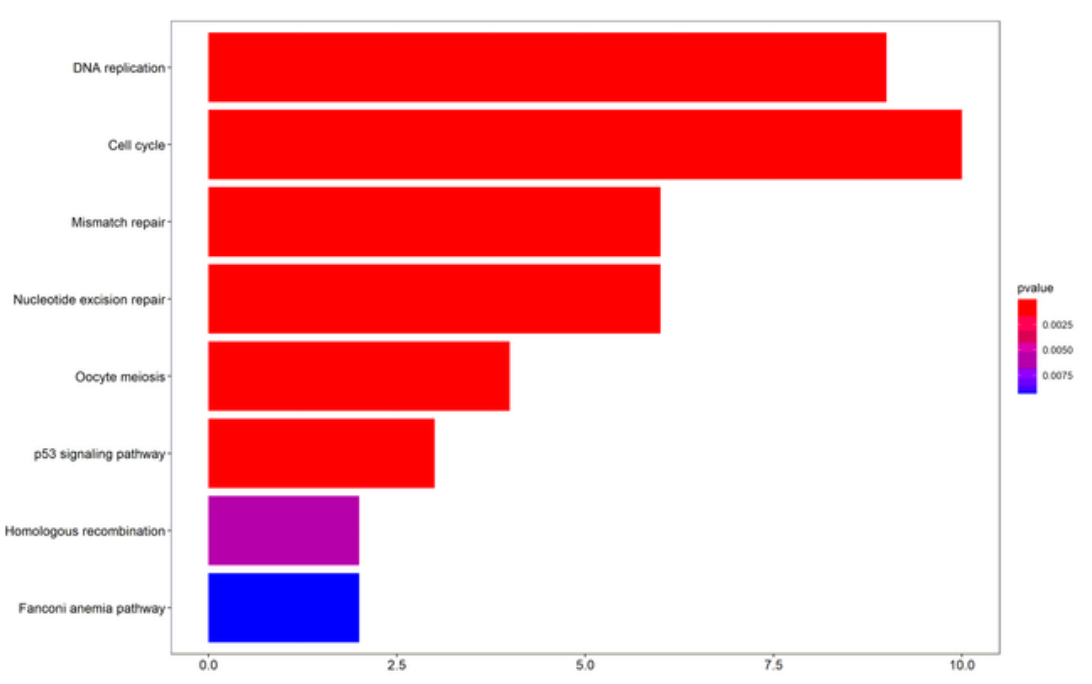

B
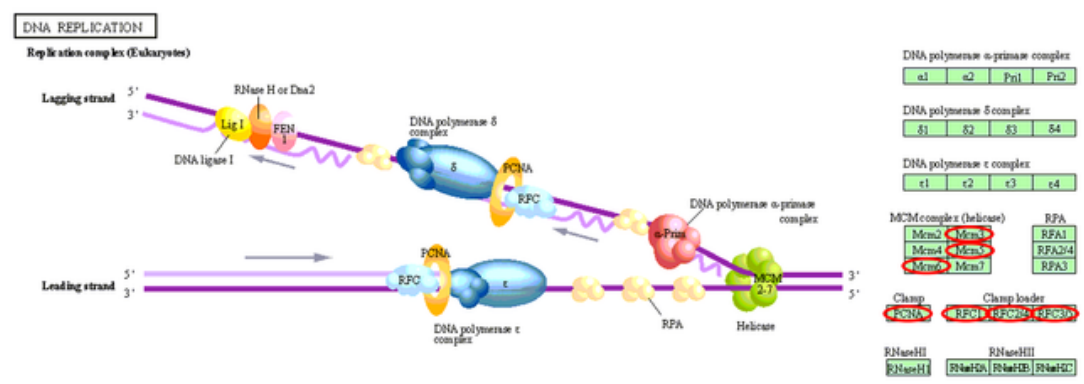

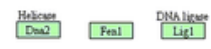

C

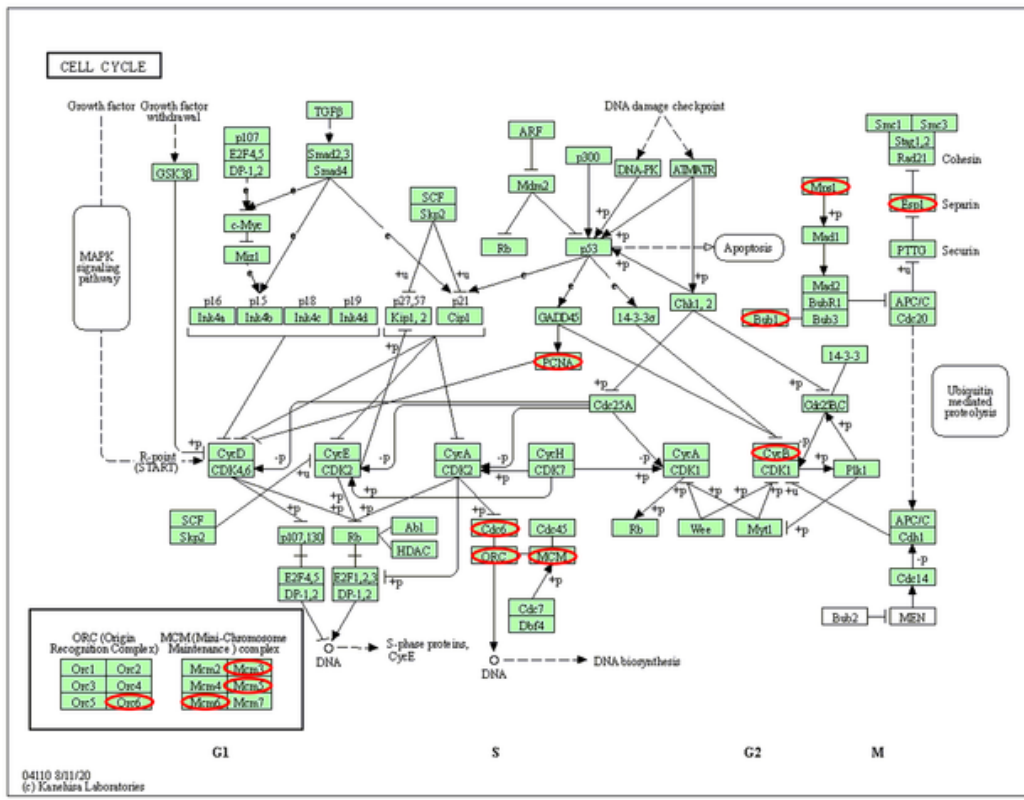

\section{Figure 8}

KEGG enrichment of RFCs and 50 frequently altered neighbor genes. (A) The KEGG enriched pathways of RFCs and 50 frequently altered neighbor genes. (B) DNA replication pathway regulated by RFCs alteration in low-grade glioma. (C) Cell cycle pathway regulated by RFCs alteration in low-grade glioma. 
A
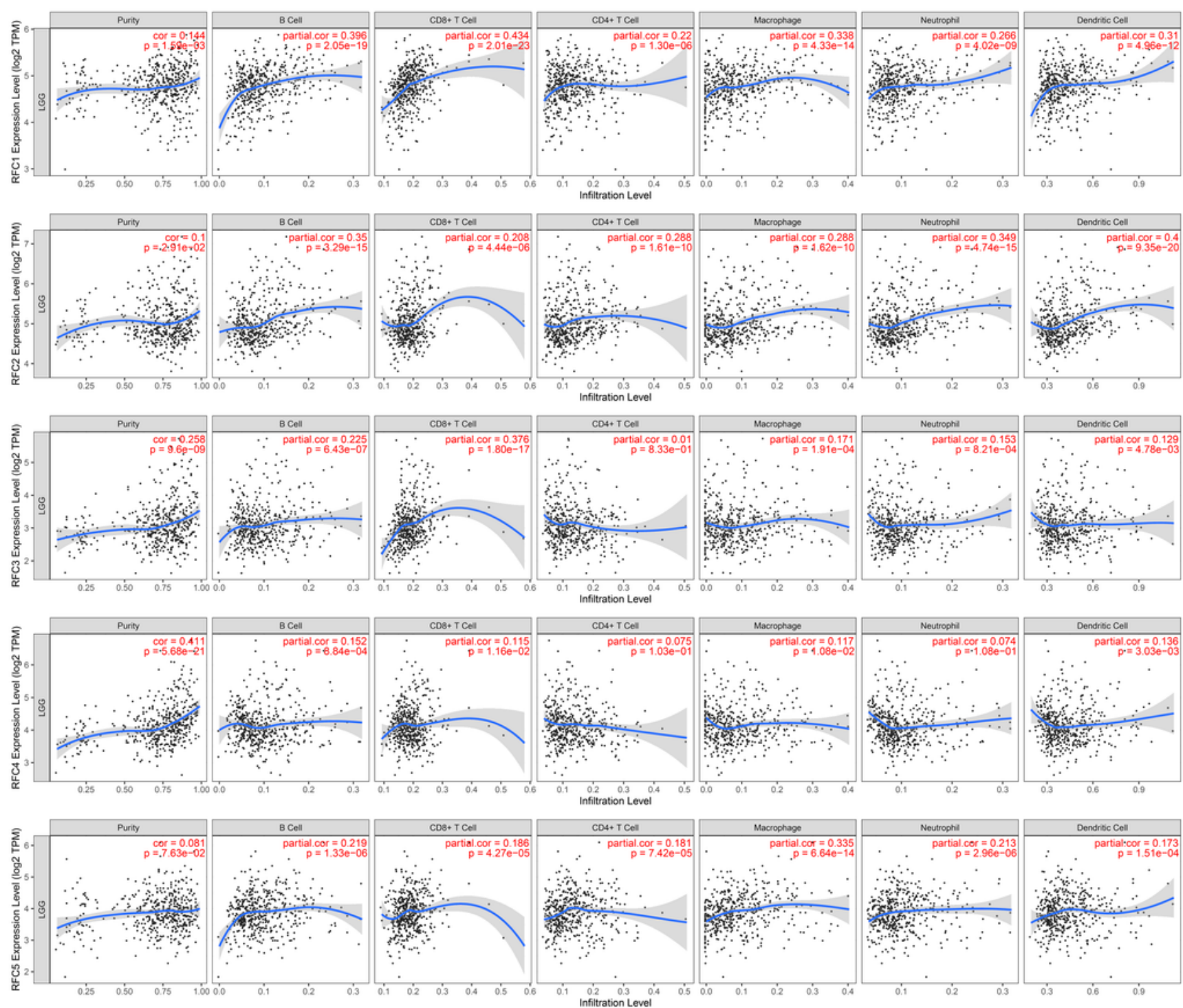

B
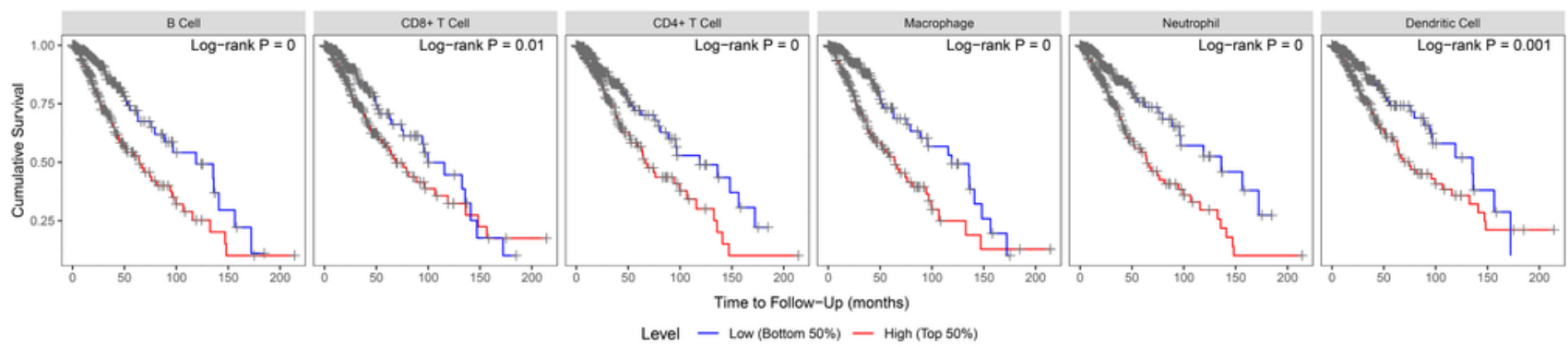

\section{Figure 9}

The correlation between different expressed RFCs and immune cell infiltration.

\section{Supplementary Files}

This is a list of supplementary files associated with this preprint. Click to download. 
- Additionalfile1.xIsx

- Additionalfile2.xIsx 